\title{
Reflective Writing about Near-Peer Blogs: A Novel Method for Introducing the Medical Humanities in Premedical Education
}

\author{
Rachel Conrad Bracken ${ }^{1}$ (D) Ajay Major ${ }^{2} \cdot$ Aleena Paul $^{3} \cdot$ Kirsten Ostherr $^{4}$
}

Accepted: 12 March 2021 / Published online: 19 April 2021

(C) The Author(s) 2021

\begin{abstract}
Narrative analysis, creative writing, and interactive reflective writing have been identified as valuable for professional identity formation and resilience among medical and premedical students alike. This study proposes that medical student blogs are novel pedagogical tools for fostering peer-to-peer learning in academic medicine and are currently underutilized as a near-peer resource for premedical students to learn about the medical profession. To evaluate the pedagogical utility of medical student blogs for introducing core themes in the medical humanities, the authors conducted qualitative analysis of one hundred seventysix reflective essays by baccalaureate premedical students written in response to medical student-authored narrative blog posts. Using an iterative thematic approach, the authors identified common patterns in the reflective essays, distilled major themes, coded the essays, and conducted narrative analysis through close reading. Qualitative analysis identified three core themes (empathic conflict, bias in healthcare, and the humanity of medicine) and one overarching theme (near-peer affinities). The premedical students' essays demonstrated significant self-reflection in response to near-peer works, discussed their perceptions of medical professionalism, and expressed concerns about their future progress through the medical education system. The essays consistently attributed the impact of the medical student narratives to the authors' status as near-peers. The authors conclude that reading and engaging in reflective writing about near-peer blog posts encourages premedical students to develop an understanding of core concepts in the medical humanities and promotes their reflection on the profession of medicine. Thus, incorporating online blogs written by medical trainees as narrative works in medical humanities classrooms is a novel pedagogical method for fostering peer-to-peer learning in academic medicine.
\end{abstract}

Keywords Narrative medicine $\cdot$ Premedical education $\cdot$ Near-peer learning $\cdot$ Reflective writing $\cdot$ Blogs

Rachel Conrad Bracken rbracken@neomed.edu

Extended author information available on the last page of the article 


\section{Introduction}

The emergence of the mobile, social web in the early 2000s fundamentally changed how students learn, from K-12 through continuing medical education (Ruiz, Mintzer, and Leipzig 2006). A prominent feature of this new pedagogical landscape is the growth of digitallyconnected peer networks for sharing resources and information. Recent research has shown the value of blogs and social media for fostering peer-to-peer learning in academic medicine (Lockspeiser et al. 2008; Cheston, Flickinger, and Chisolm 2013; Goldie 2016). As compared to teaching by senior clinical faculty, peer-to-peer and near-peer learning offer novel approaches to a range of objectives, including enhancing awareness of sociocultural context (Tamachi et al. 2018), improving clinical skills (Chou and Teherani 2017), increasing anatomical knowledge (Agius et al. 2018), and transitioning to clerkships (Knobloch et al. 2018). Within the traditionally hierarchical context of medical education, online peer communities can enable previously unheard voices, such as medical trainees, to gain expression (Eysenbach 2008). Further, research has demonstrated the value of studying online medical student communities on platforms such as WhatsApp to better understand the concerns of participants in real-time and in a social context (Coleman and O'Connor 2019).

Research on peer learning through online communities builds on literature in the field of narrative medicine. The practices of studying and creating narratives (Charon, Hermann, and Devlin 2016) have been identified as valuable methods for fostering some of the Core Competencies for Entering Medical Students established by the Association of American Medical Colleges (AAMC), such as empathy and ethical responsibility (Association of American Medical Colleges, "The Core competencies for Entering Medical Students"). Baruch (2013) has argued that creative writing should be seen as a medical instrument that provides "tools for clinical excellence and empathy" (459). Wald and colleagues (2019) argue that interactive reflective writing can help develop professional identity and resilience in medical students, while Lamothe and colleagues (2014) suggest that this practice may be protective against burnout. In addition to its role in medical education, Kanter (2008) has demonstrated that the practice of narrative medicine can be successfully used with students in the baccalaureate premedical setting, which offers more time and space to develop independent, creative thinking skills as well as strong moral reasoning and a commitment to social justice.

The availability of public blogs written by medical students as they reflect on their experiences in training provides a unique opportunity for premedical students to gain insight from near-peers about their intended profession and to hone the practice of reflective writing. Thus, extending foundational research in narrative medicine, this study hypothesized that medical student blogs present an underutilized opportunity for medical educators - and other students - to gain insights into the qualitative aspects of their experience. To test our hypothesis that near-peer narratives prompt valuable reflection on professional identity development and provide a novel means to introduce core medical humanities concepts to premedical undergraduates, we conducted a qualitative study that examined students' responses to creative nonfiction narratives written by medical students for an online blog.

\section{Methods}

This qualitative study was conducted in the context of an introductory, baccalaureate premedical humanities course. We assigned a set of readings that were originally written for an online, peer-reviewed blog run by and for medical students called in-Training (https:// 
in-training.org/); these blog posts were later published as an edited collection by the same name (Major and Paul 2016). The authorship of the essays by near-peer medical students was not explicitly emphasized by the instructor. Students in the course were assigned seventeen short pieces (approximately five hundred words each) from in-Training alongside readings from widely used scholarly sources in the field of medical humanities, including anthologies edited by Cole et al. (2015) and Jones, Wear, and Friedman (2014), over the course of a fourteen-week semester (see Table 1 for a list of blog post titles). The readings were selected to supplement analytical essays assigned to address the five thematic units of the course: The History of Medicine and "Disease" vs. "Illness," Narrative Medicine, Disability and Health Disparities, Science and Technology, and Religion and Spirituality.

Our dataset consisted of 176 reflective essays written by sixty-two premedical students over the course of four semesters (August 2016 to April 2018). Study participants consisted of zero first-year students, twelve (20\%) sophomores, twenty-two (37\%) juniors, and twenty-six $(44 \%)$ seniors. The majority of students $(n=44,73 \%)$ were Natural Sciences majors, followed by Social Sciences $(n=11,18 \%)$, Humanities $(n=9,15 \%)$, and Engineering $(n=3,5 \%)$. The numbers of majors do not add up to $100 \%$ due to the participation of students pursuing double majors. Students were assigned to read seventeen in-Training blog posts, and then select three of them to explore through short, critical written reflections of approximately 250-500 words. The number of reflections written about each inTraining blog post is displayed in Table 1.

Our qualitative analysis was conducted in two stages. First, the research team identified which in-Training blog posts were selected by the premedical students for their reflective writing. Next, we sought to identify the predominant themes that emerged from the reflective essays. We began by reading through all of the essays to deductively identify a broad range of important themes. We identified approximately twenty to thirty initial themes and, on the basis of discussion, reached consensus about terminology that could be used to cluster and distill conceptually similar themes into three, comprehensive thematic categories: empathic conflict, bias in healthcare, and the humanity of medicine. We used these categories to code the dataset of 176 essays, with each essay coded by two reviewers. We collaboratively verified consistent application of codes through regular team meetings throughout our analysis. All of the coded essay segments were then subjected to narrative analysis by two members of the research team using close reading methods to explore the premedical students' engagement with near-peer medical student writings, which revealed an additional, overarching theme: near-peer affinities.

\section{Results}

Evidence of the pedagogical value of integrating near-peer narratives into a baccalaureate medical humanities course emerged from deductive, iterative analysis of our dataset. The premedical students focused their reflective writings on three major themes: empathic conflict, bias in healthcare, and the "humanity of medicine" (Pham 2012). In addition, a fourth, overarching theme of near-peer affinities appeared across all three of the major themes. We present the results of our narrative analysis of these themes below. Illustrative quotes from premedical student essays are referenced by the semester and year followed by the essay number (for example, F16-8 represents an essay written in the Fall semester of 2016, with the randomly assigned numerical identifier of 8). Selected quotations from student reflections are compiled in Table 2. 


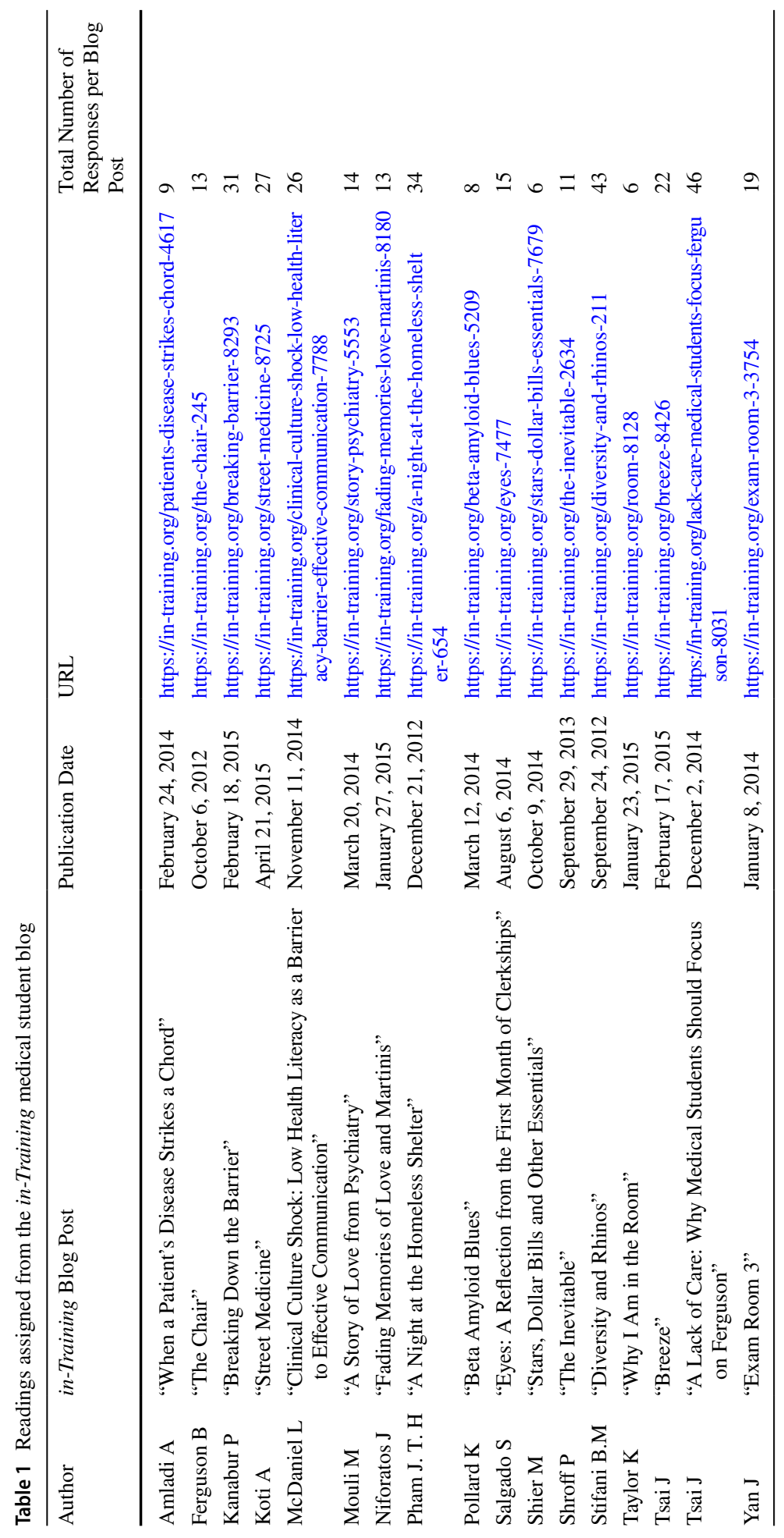




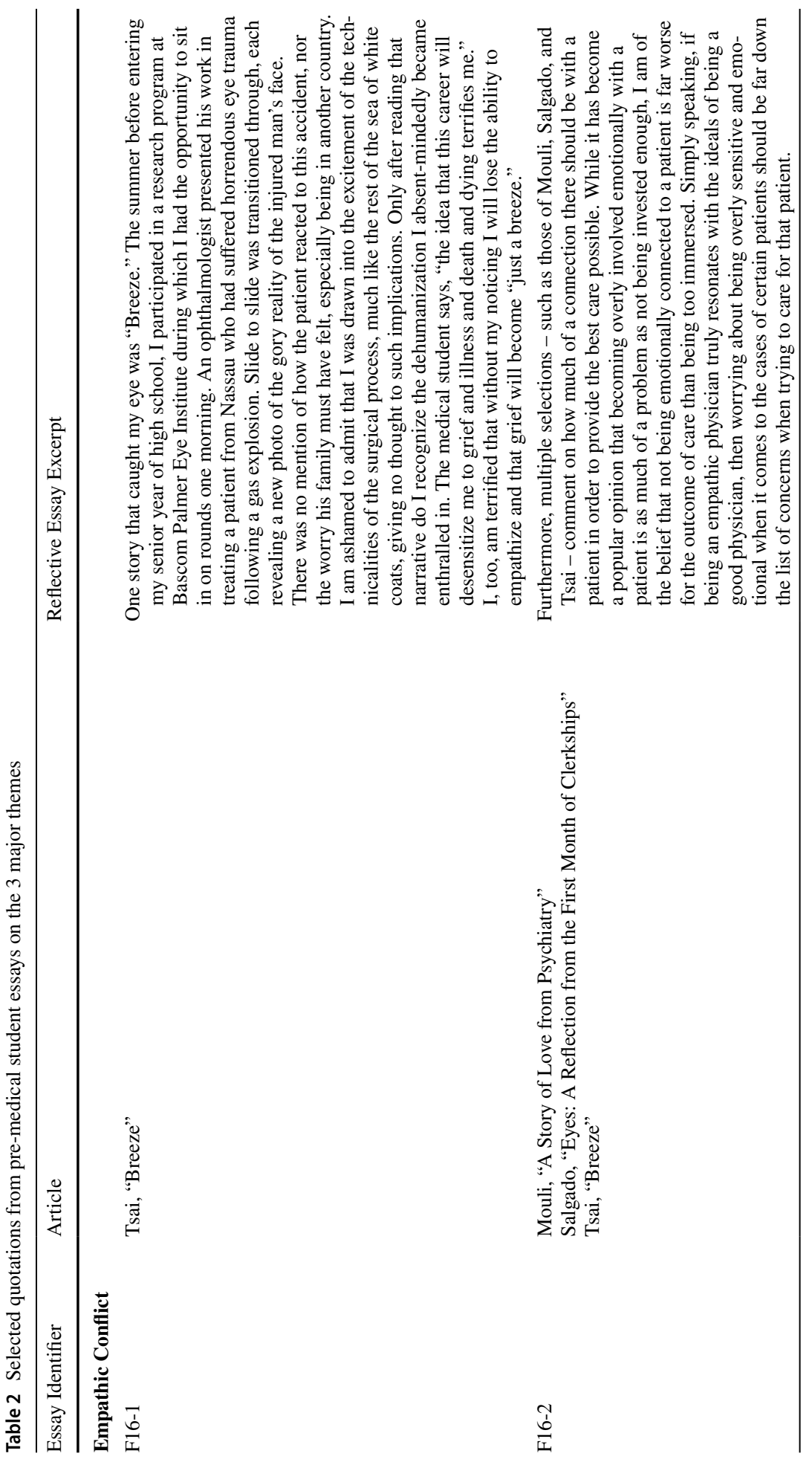




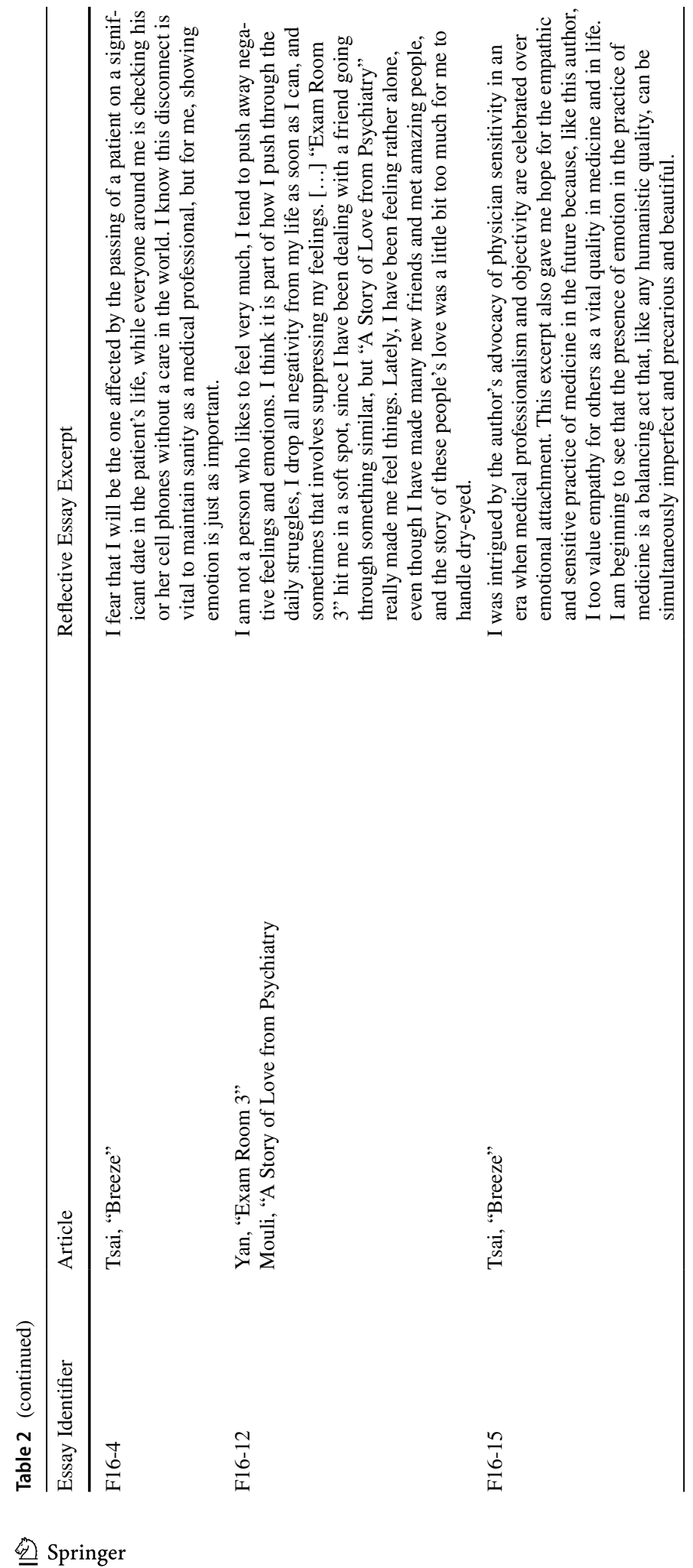




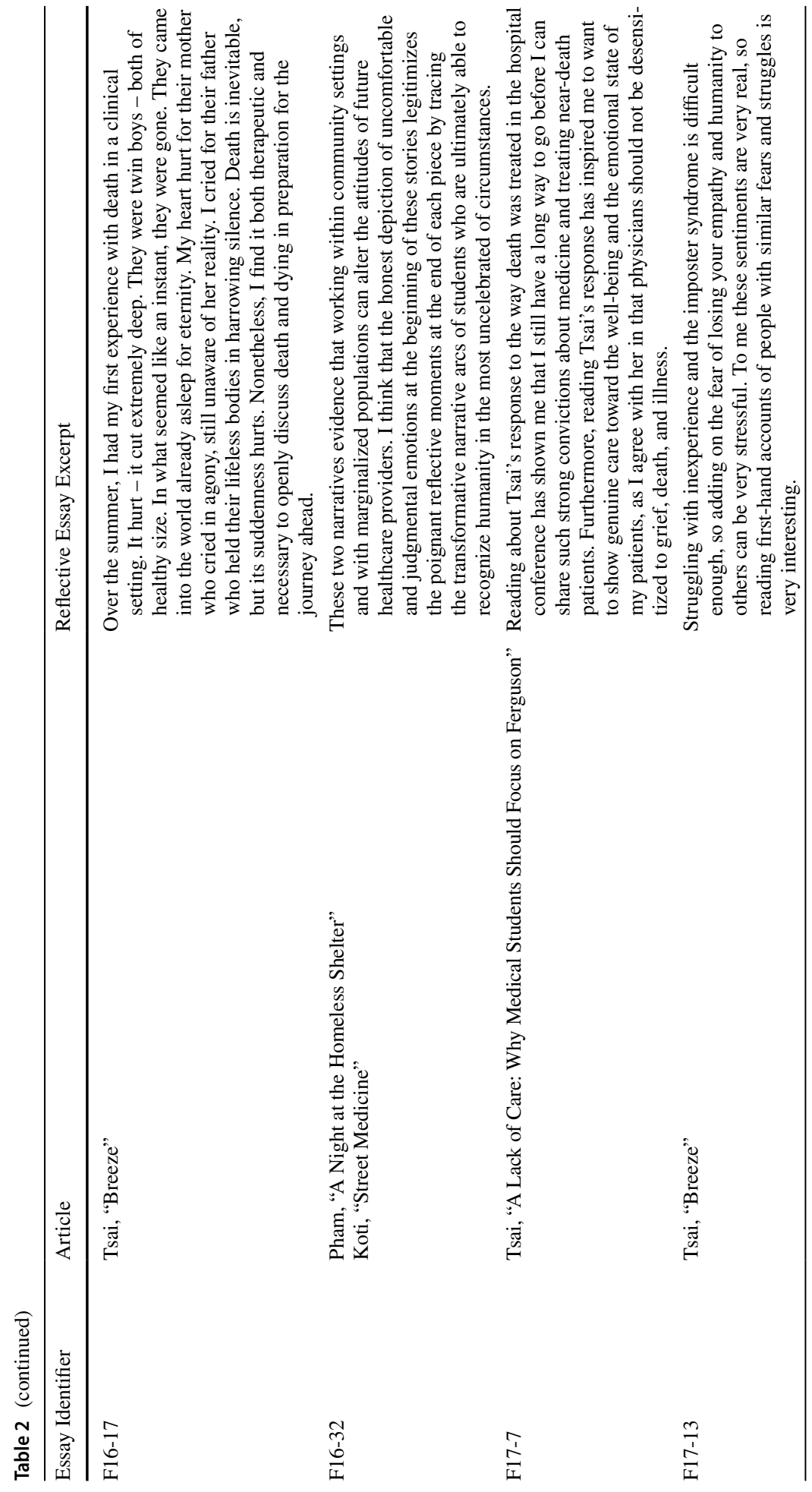




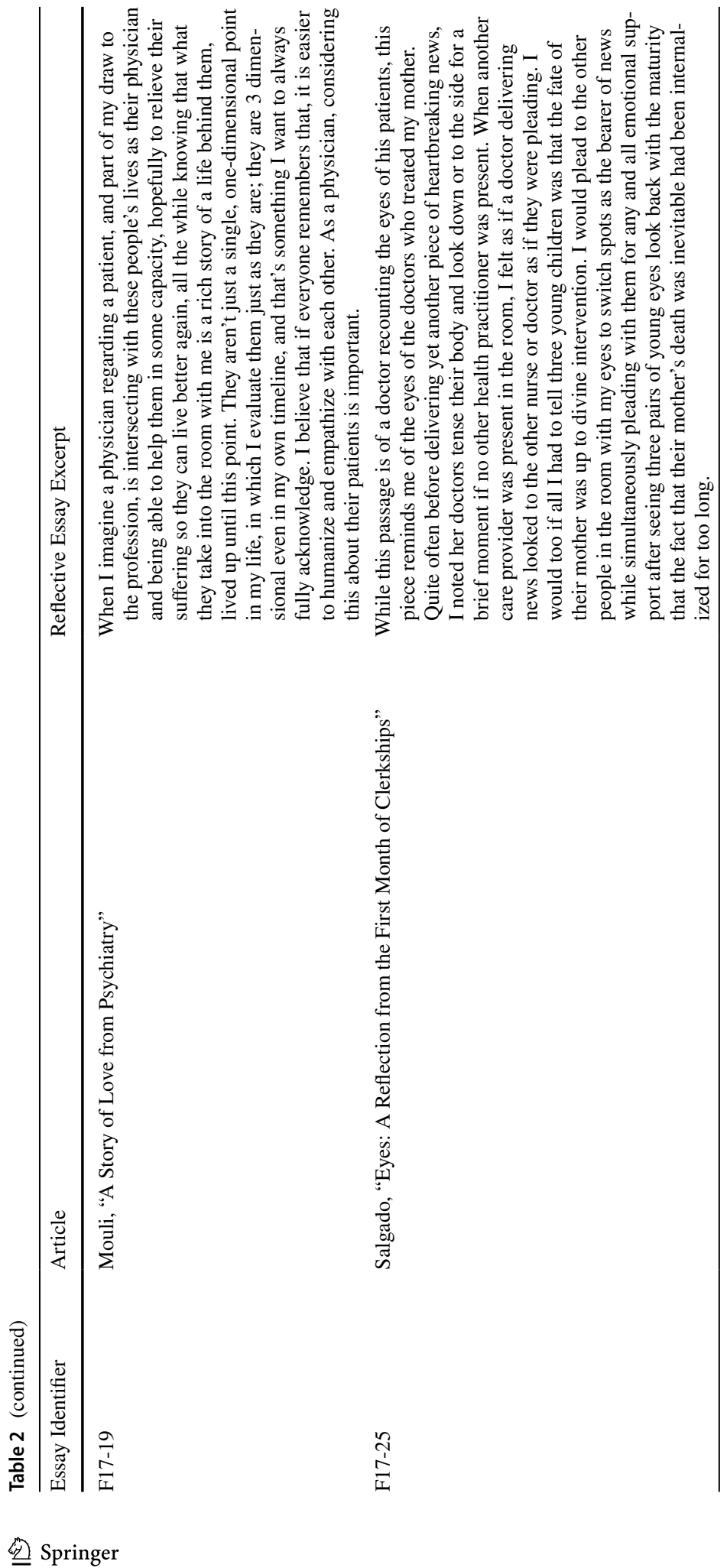




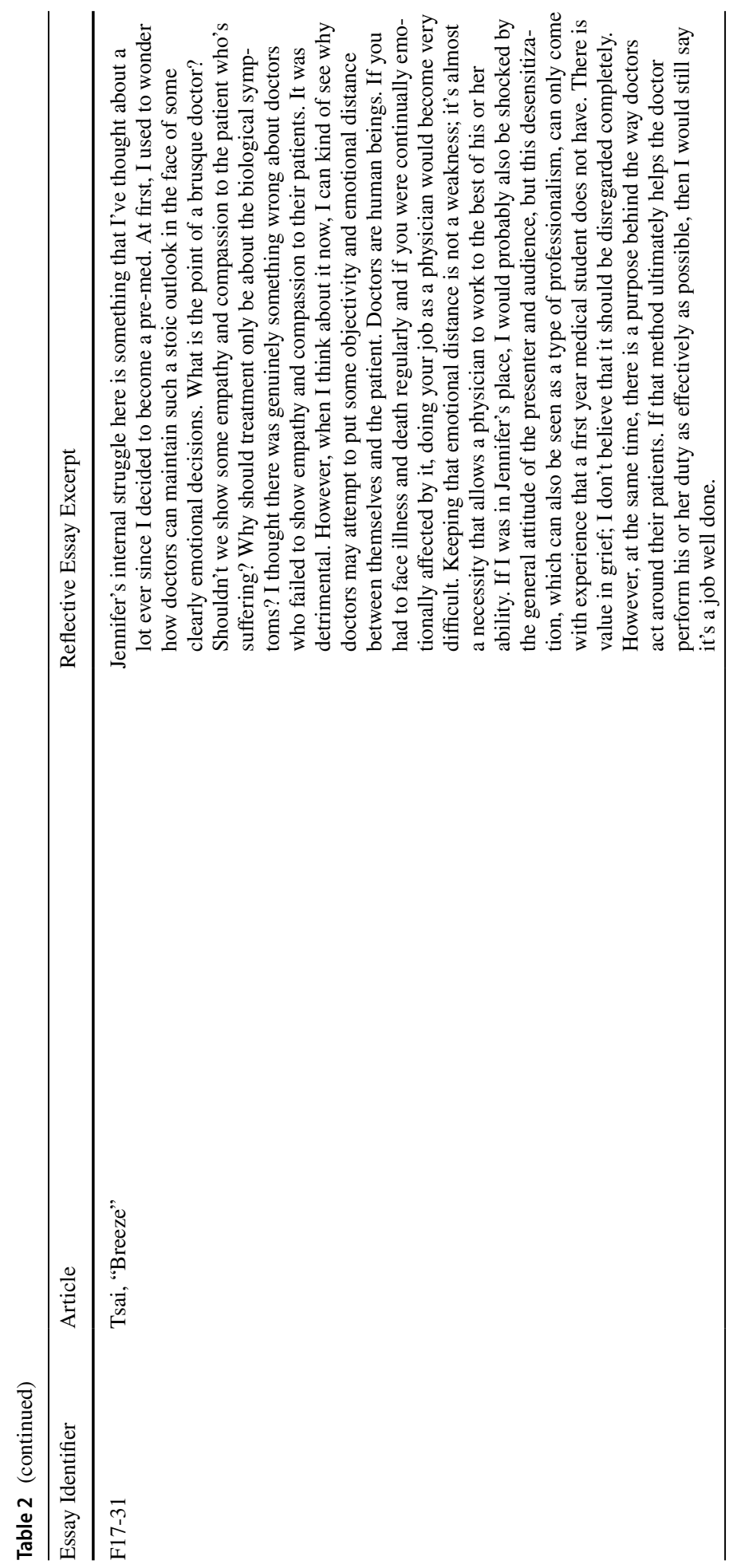




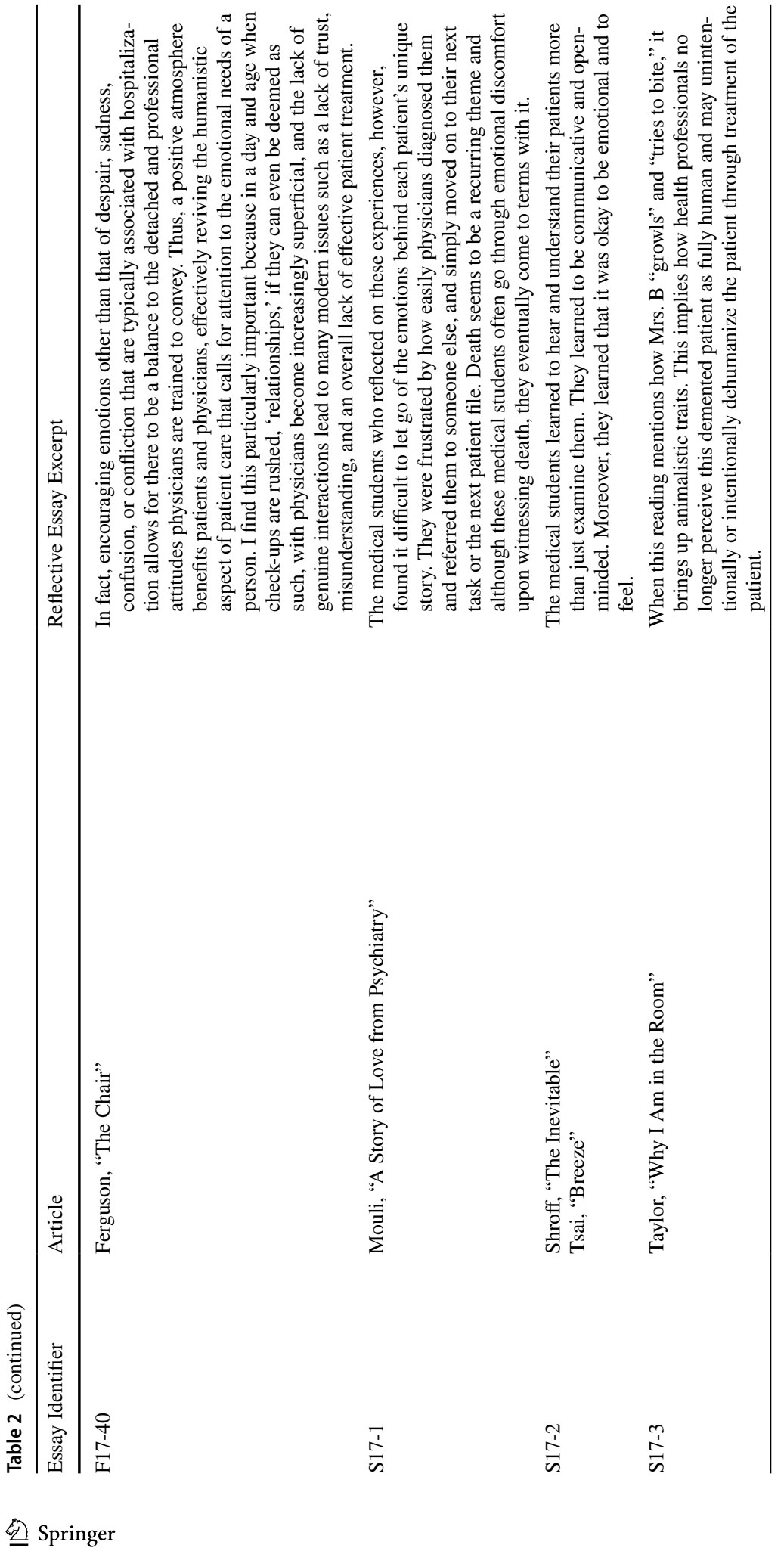




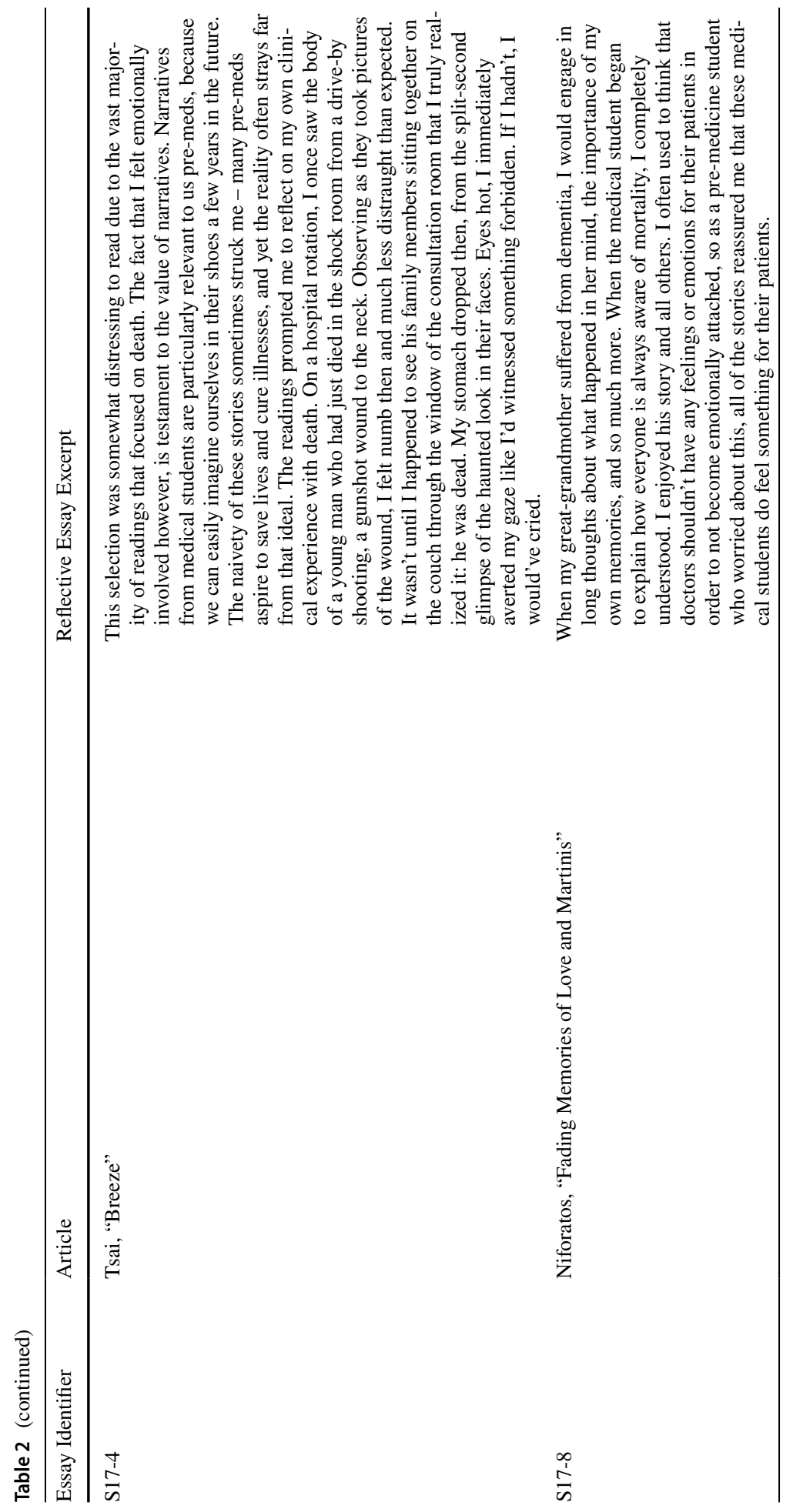




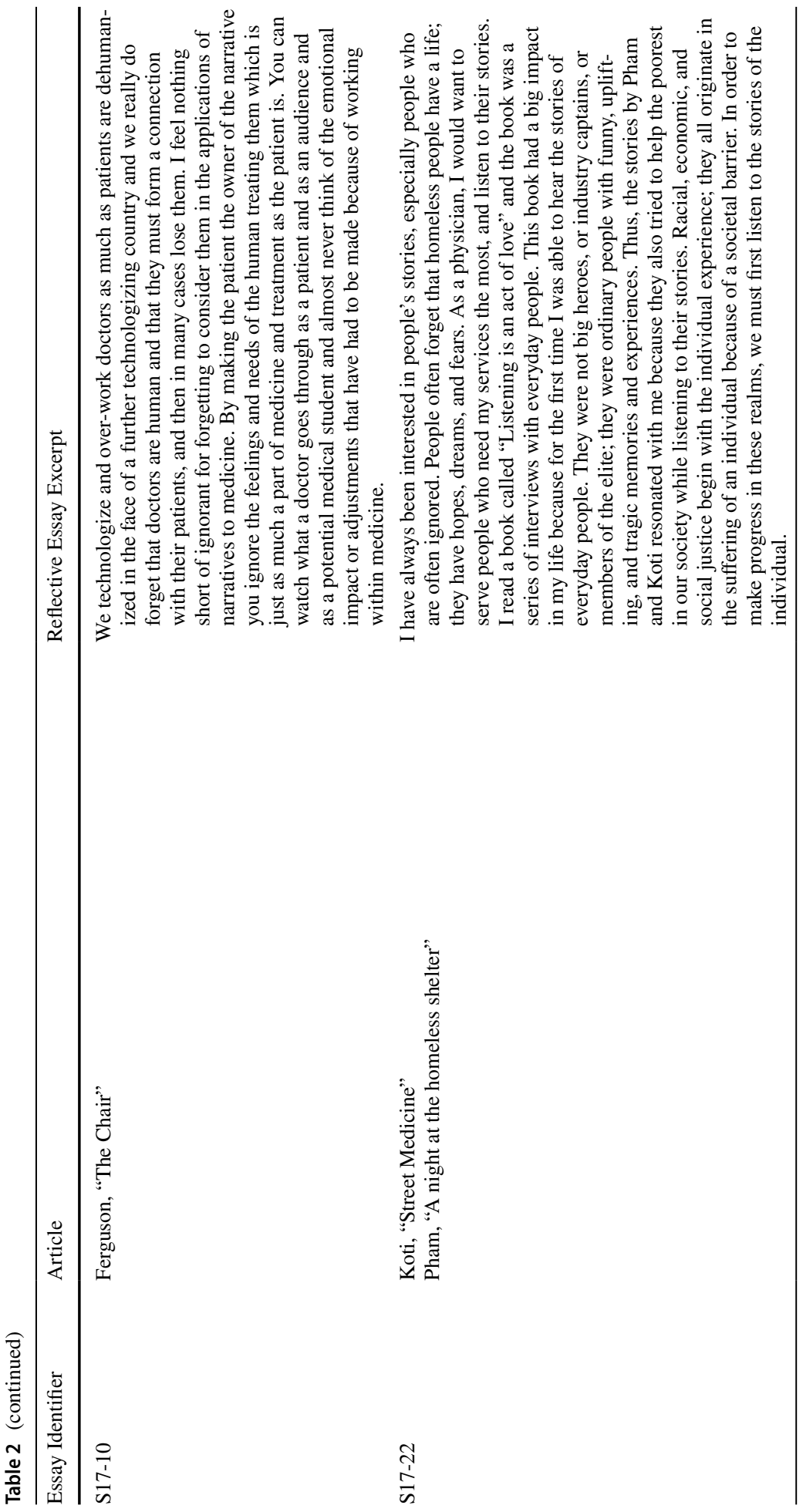




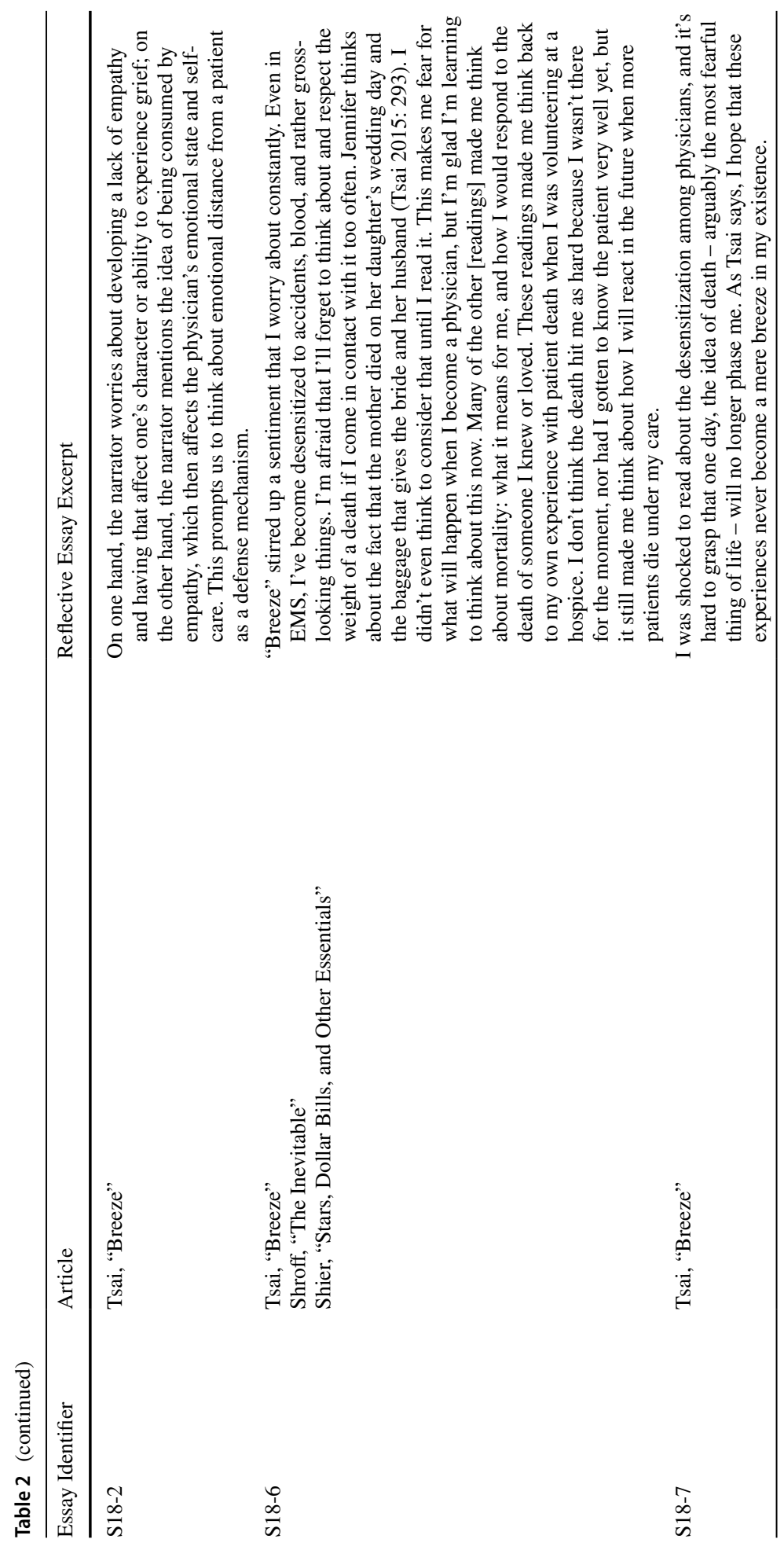




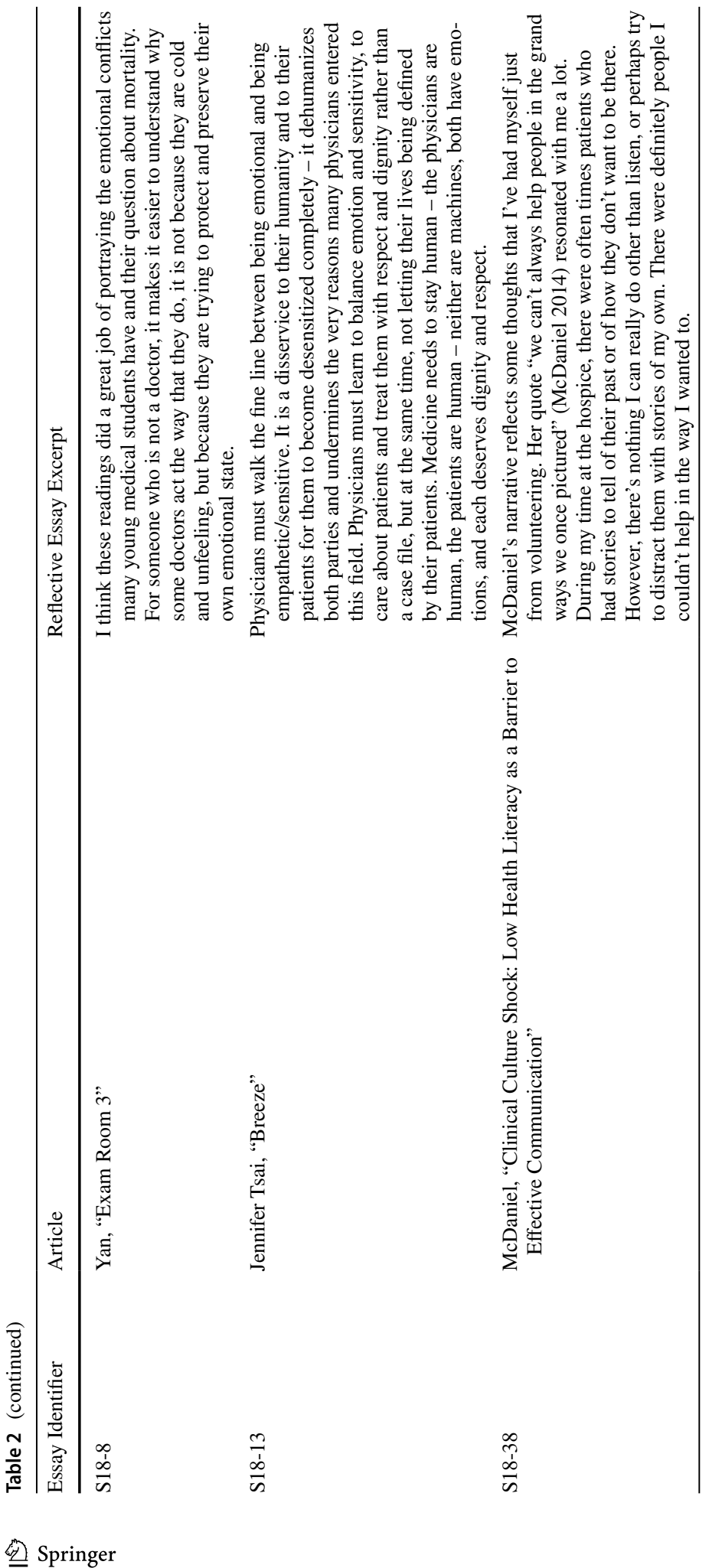




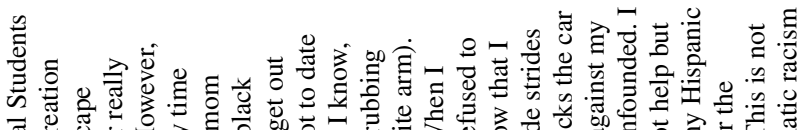

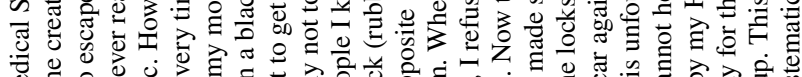

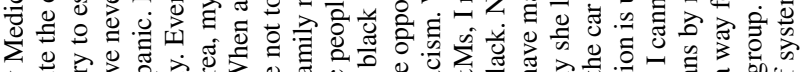

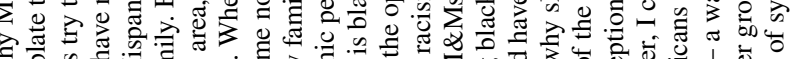

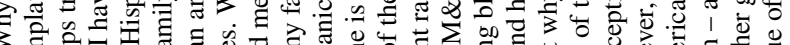

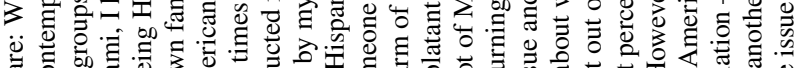

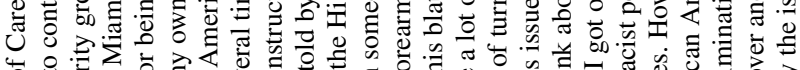

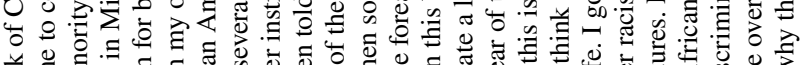

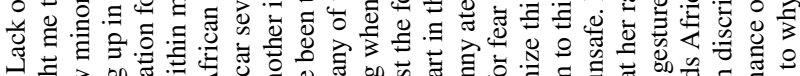

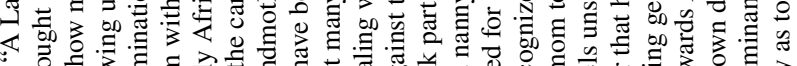

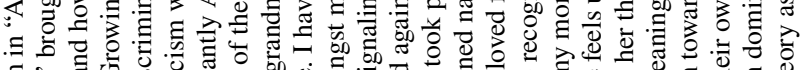

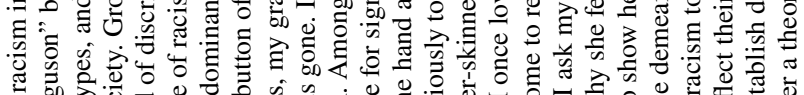

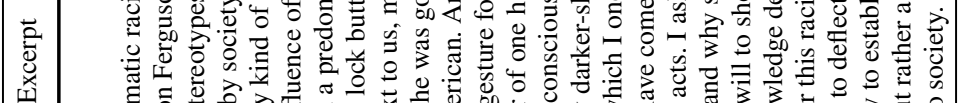

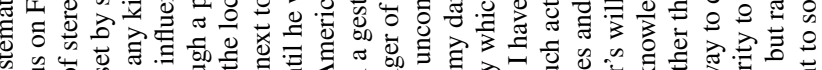

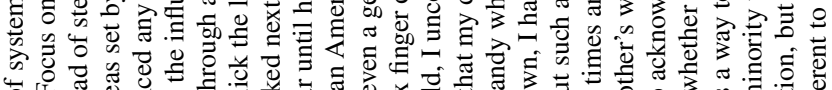

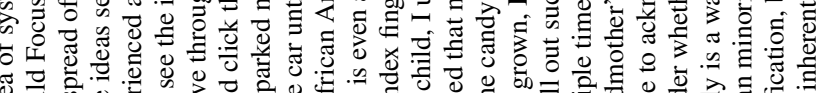

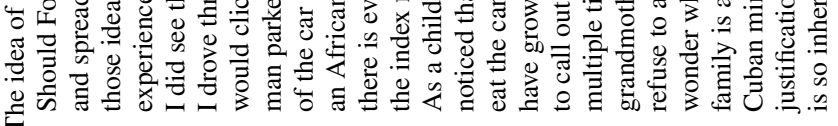

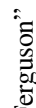

童

ธ

岂

吾

ज़

芠

क

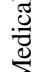

ह

نั

4

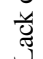

날

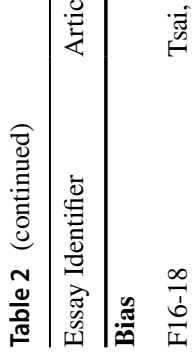




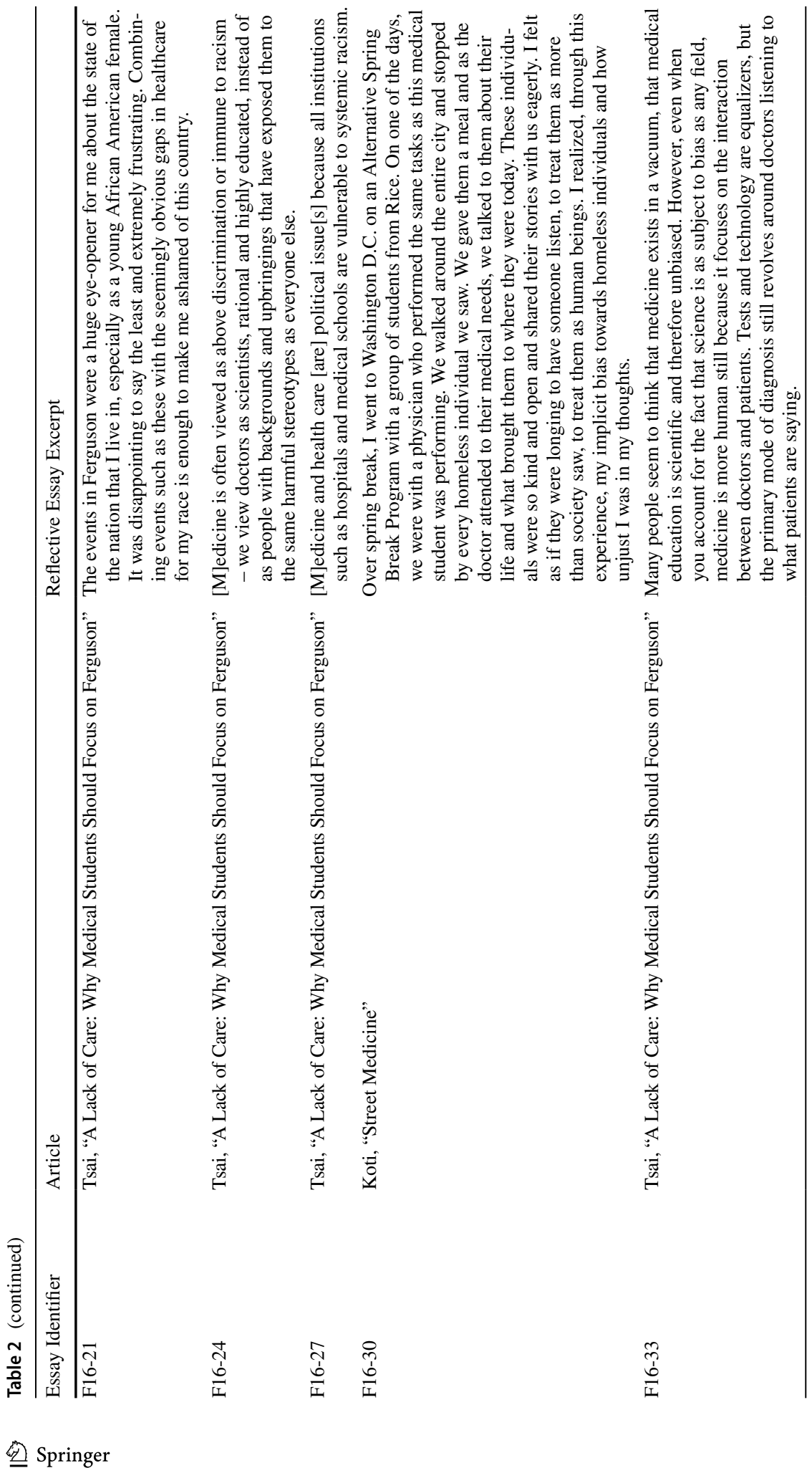




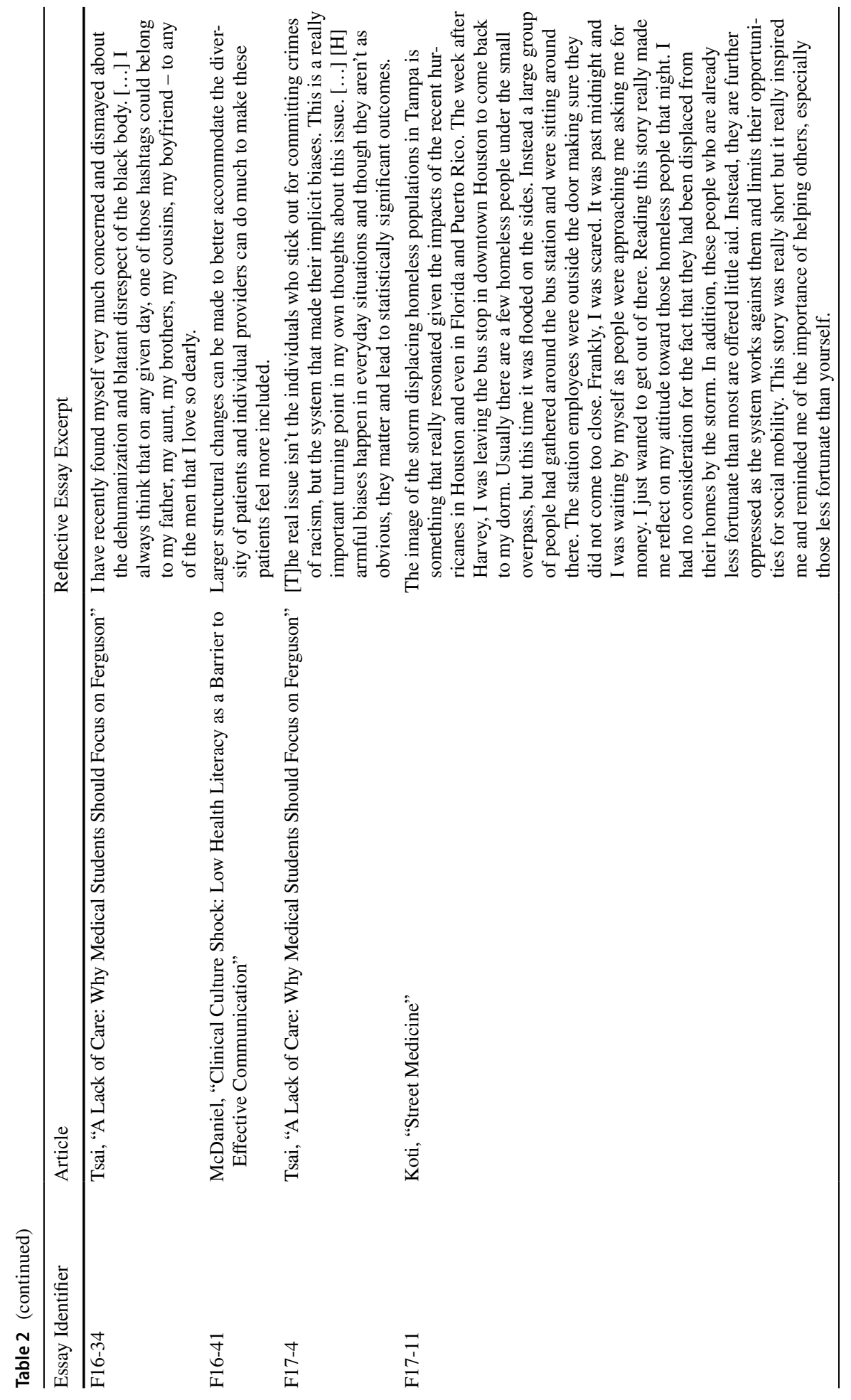




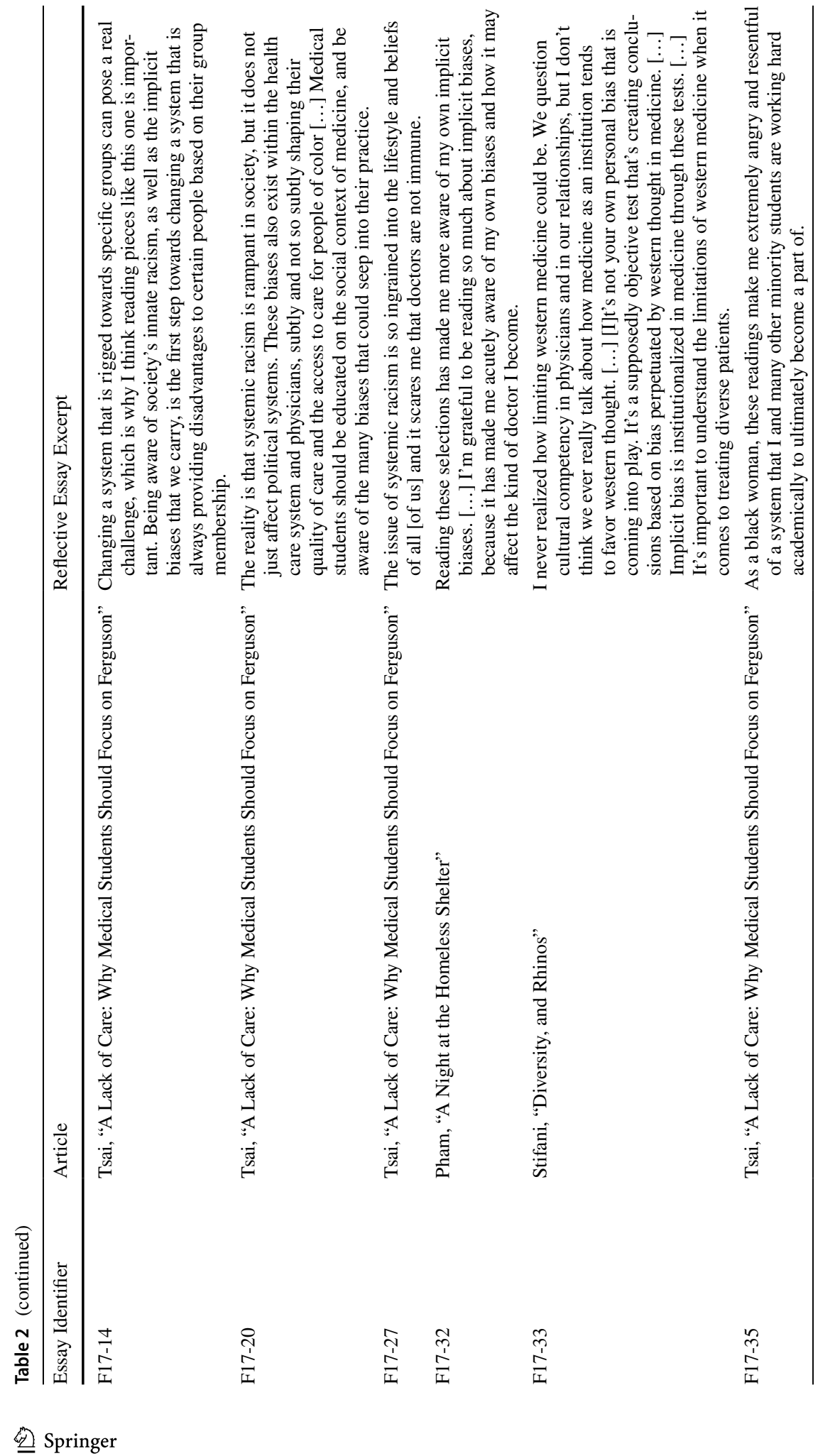




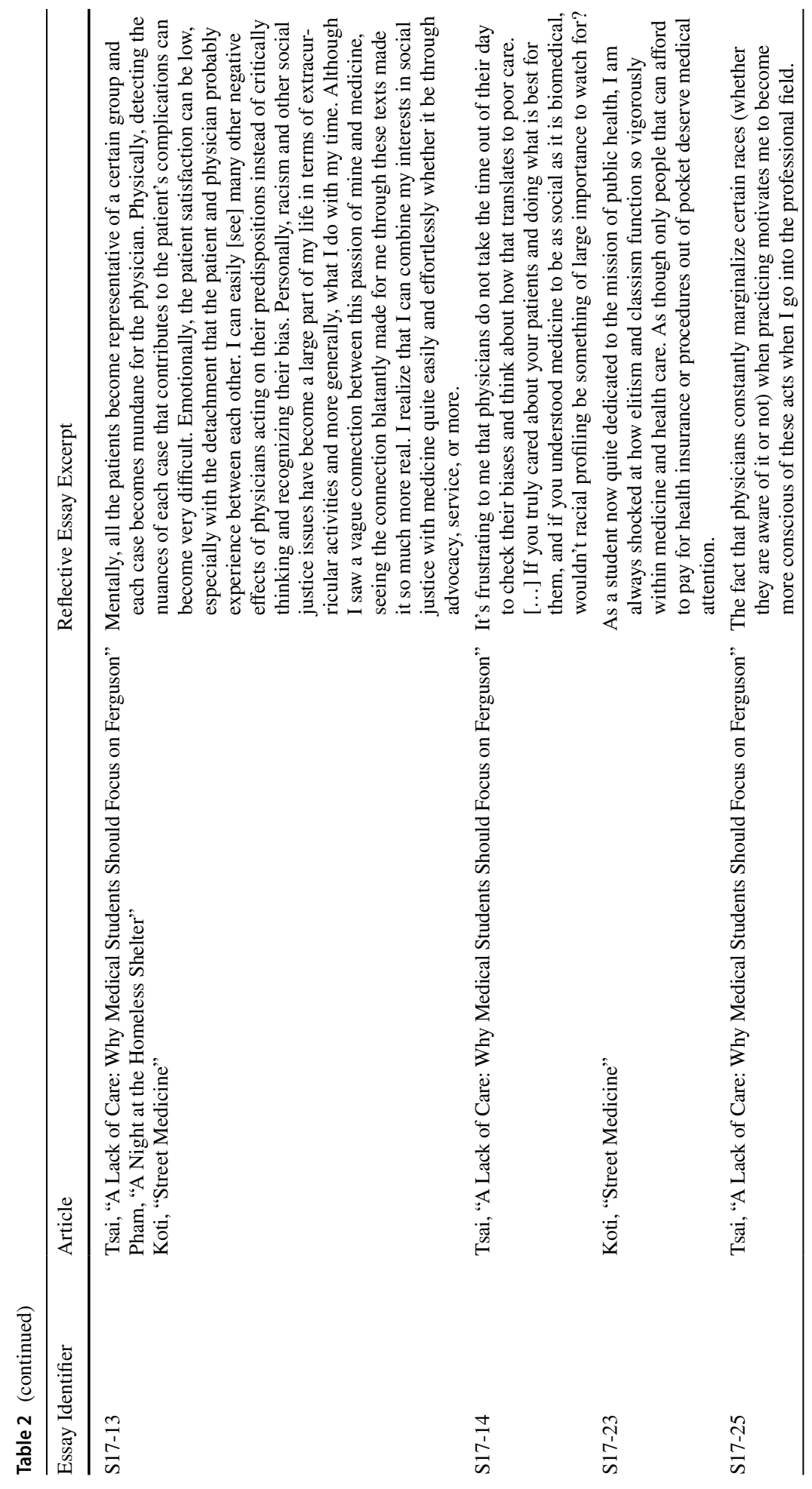




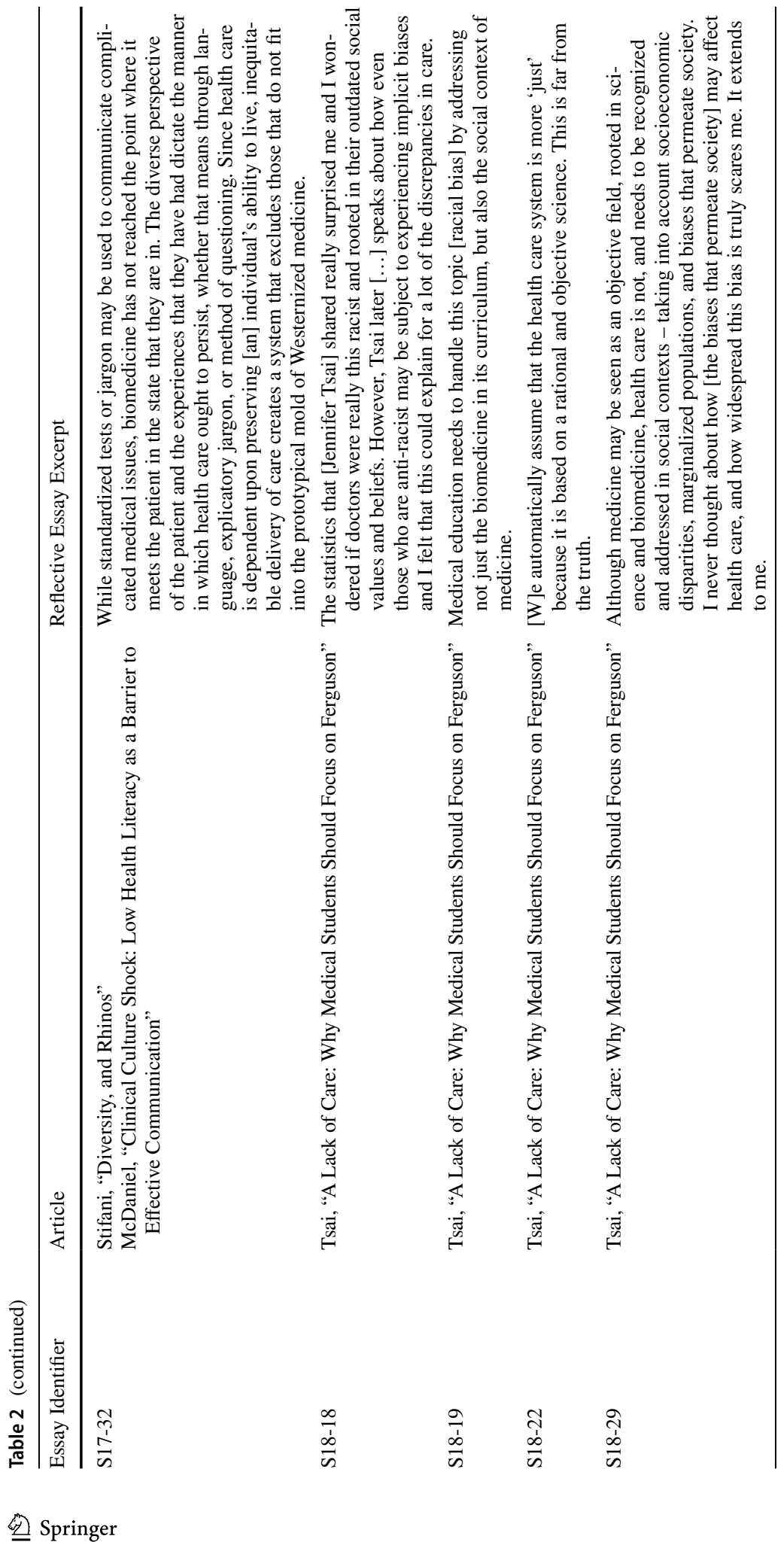




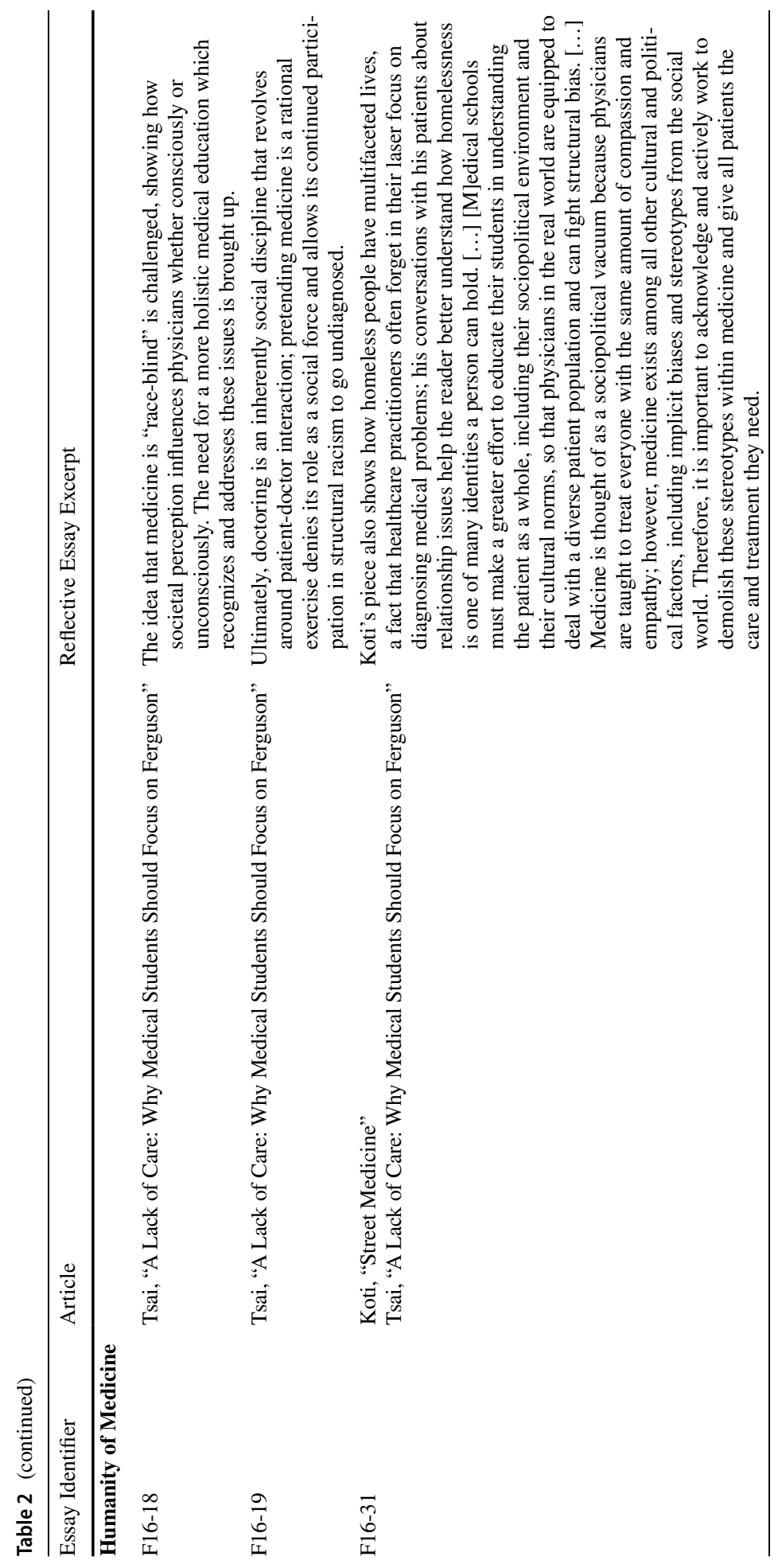




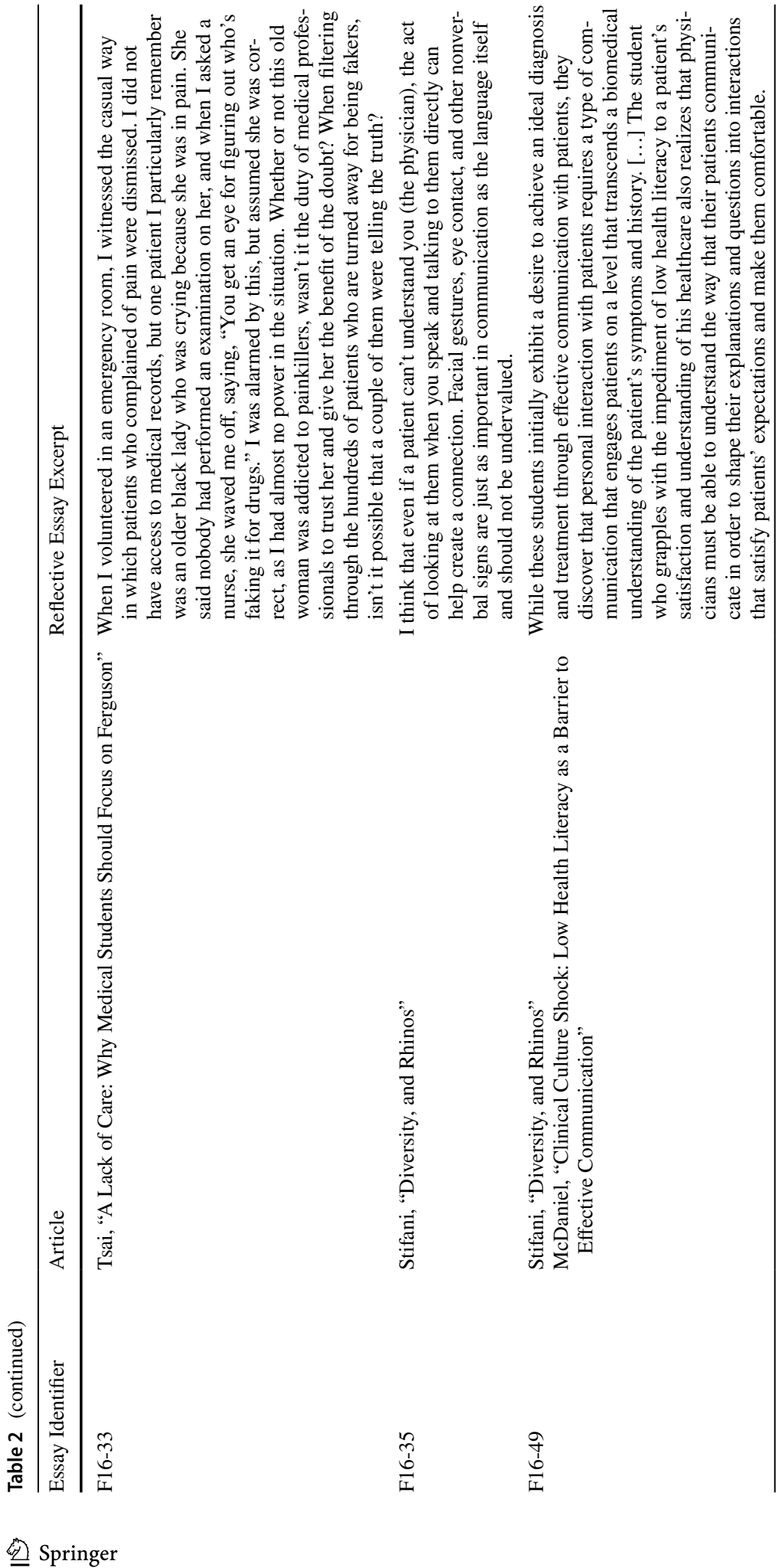




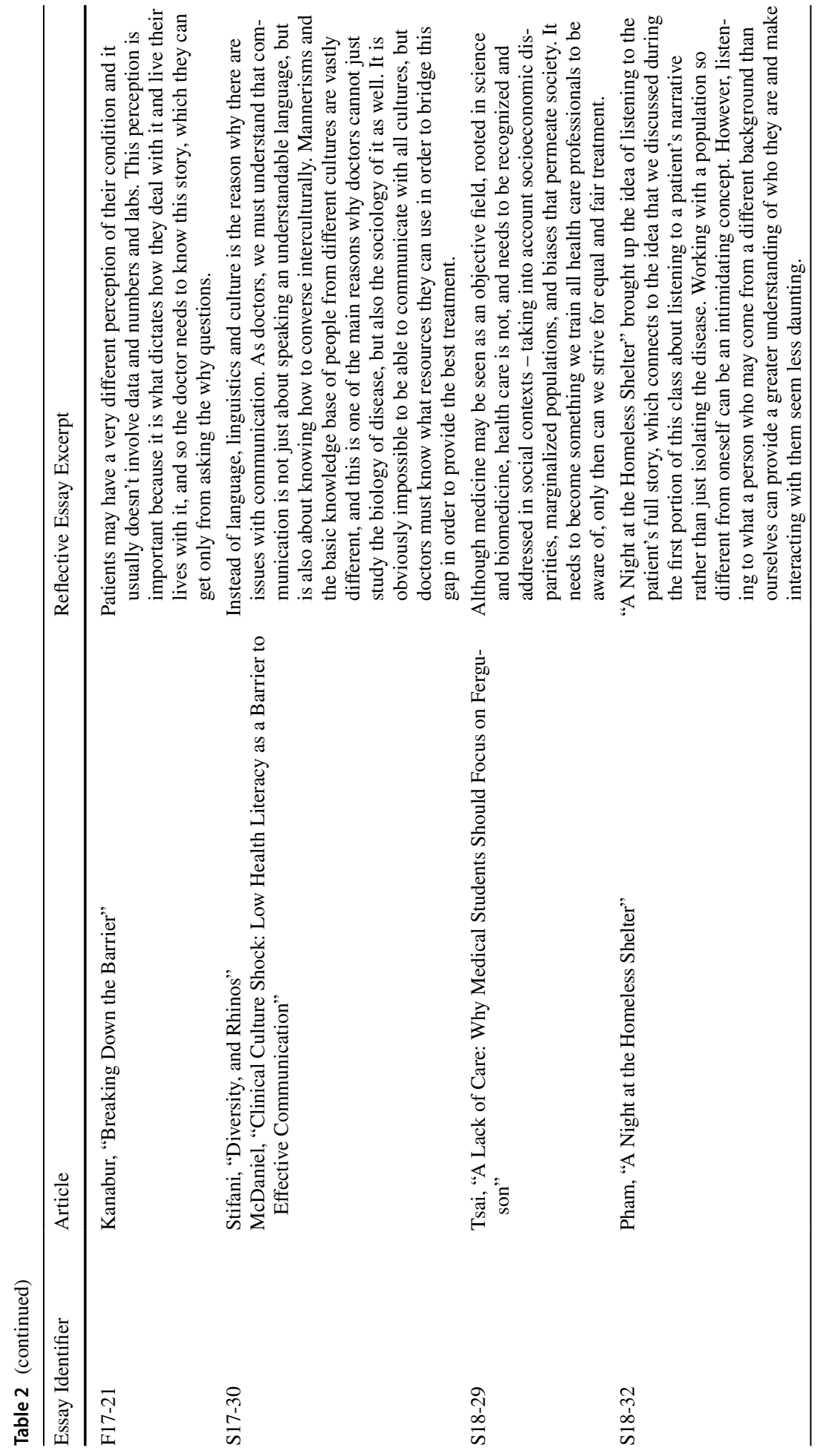




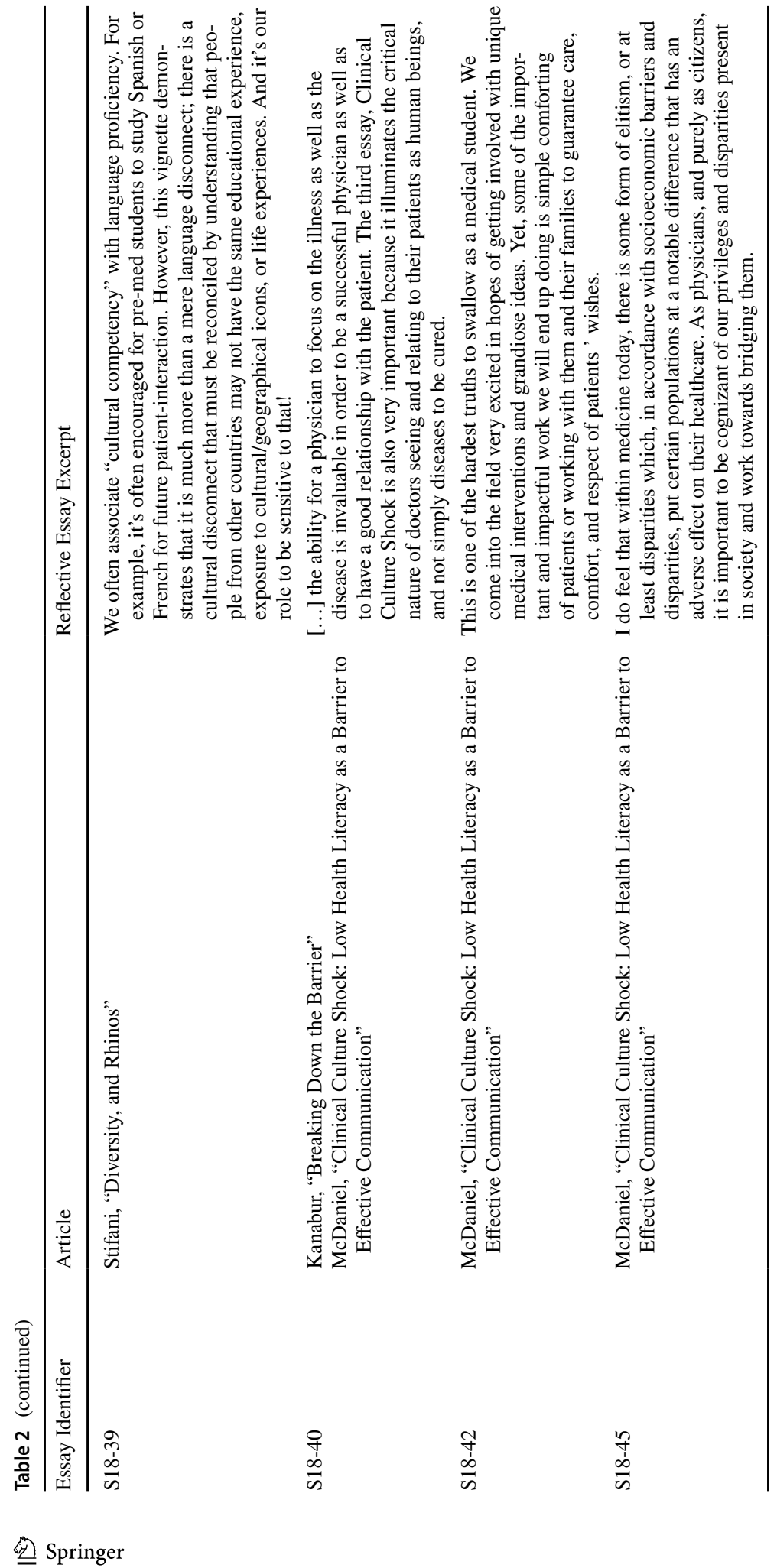




\section{Theme 1: empathic conflict}

In their essays, premedical students emphasized the theme of empathic conflict, focusing on the difficult balance between expressing emotion and empathy towards patients while maintaining an appropriate professional distance. Responses discussed how emotional expression enhanced the practice of medicine for both patients and physicians (F16-2, S171, S17-2, F17-40). Study participants reflected on the professional costs of empathic conflict and identified depersonalization, dehumanization, and emotional fatigue in the medical students' blog posts (F16-1, S18-6, S18-7, S17-3). Students frequently reflected on the medical trainees' challenge of balancing their emotional attachment to patients with a professionally appropriate empathetic response (F16-2), and expressed concern that achieving this balance would be challenging in their future careers (S18-6, F16-4, F16-15, S17-1, F17-31, S18-13). Several essays noted that emotional distancing was a defense mechanism (S18-2, S18-8) and that imposter syndrome was closely related to issues of empathic conflict and burnout (F17-7, F17-13). Students identified the importance of patient narratives in the practice of medicine (S17-4, S17-8, S17-10, S17-12, S17-22), and discussed the role these narratives may play in protecting the empathic wellbeing of medical students (F16-32, F17-19). Several essays also revealed how the near-peer blog posts exposed the students' own internal empathic conflicts or conflicts they had personally witnessed in their interactions with other patients or clinicians, and how reflecting on those narratives allowed them to process their own emotions and empathy (S17-4, F16-1, F16-12, F16-17, F17-25, S18-38).

Jennifer's internal struggle here is something that I've thought about a lot ever since I decided to become a pre-med. At first, I used to wonder how doctors can maintain such a stoic outlook in the face of some clearly emotional decisions. What is the point of a brusque doctor? Shouldn't we show some empathy and compassion to the patient who's suffering? Why should treatment only be about the biological symptoms? I thought there was genuinely something wrong about doctors who failed to show empathy and compassion to their patients. It was detrimental. However, when I think about it now, I can kind of see why doctors may attempt to put some objectivity and emotional distance between themselves and the patient. Doctors are human beings. If you had to face illness and death regularly and if you were continually emotionally affected by it, doing your job as a physician would become very difficult. Keeping that emotional distance is not a weakness; it's almost a necessity that allows a physician to work to the best of his or her ability. (F17-31)

\section{Theme 2: bias in healthcare}

Premedical students' writings demonstrated nuanced comprehension of the ways in which bias, whether overt, implicit, or structural, is present in medicine and reflected in their own personal experiences of and beliefs about race, discrimination, structural racism, and social justice (F16-21, F16-34, S17-23, F17-27, F17-35). Their essays commented on the in-Training bloggers' descriptions of the subtle yet insidious ways that medical institutions discriminate against people of color, vulnerable populations, and marginalized cultures. The premedical students examined how their own implicit biases might influence the way that they would practice medicine in the future (F16-18, F16-30, F16-33, S17-13, S17-25, F17-11, F17-12, F17-32, S18-18, S18-29), and some advocated for coursework and training emphasizing the sociocultural dimensions of health and medicine (S17-14, F17-14, 
F17-20, S18-19). Others called attention to the need for institutional spaces and protocols better designed to serve diverse patient populations (F16-33, F16-41, S17-32, F17-33). Many students also took a broad, sociopolitical perspective on bias in healthcare, noting how systemic racism influences American medical practice, despite popular conceptions of medicine as an objective science (F16-24, F16-27, F16-33, F17-4, F17-20, S18-22, S18-29).

[T] he real issue isn't the individuals who stick out for committing crimes of racism, but the system that made their implicit biases. This is a really important turning point in my own thoughts about this issue. ... [H] armful biases happen in everyday situations and though they aren't as obvious, they matter and lead to statistically significant outcomes. (F17-4)

The fact that physicians constantly marginalize certain races (whether they are aware of it or not) when practicing motivates me to become more conscious of these acts when I go into the professional field. (S17-25)

\section{Theme 3: "the humanity of medicine"}

Premedical students reflected on the medical student blog posts by discussing the complexity of the patient-physician relationship and expressing appreciation for what they, borrowing the phrase from in-Training blogger Jimmy Tam Huy Pham, refer to as the "human side of medicine" (2012). Their essays highlighted the professional importance of listening to the patient's narrative and seeing patients as more than diseases to be cured (S18-32, S18-40). Premedical students reflected on their personal understanding of what makes a successful physician, focusing on the importance of open communication between doctors and patients, respecting patient's wishes, understanding how patients live with medical conditions, and providing comfort and care to patients and their families (F16-33, F1635, F17-21, S18-42). Several premedical students discussed aspects of medicine beyond the biomedical sciences that they recognized as critical to patient care, including social determinants of health (e.g. housing and health literacy), socioeconomic disparities, and barriers to accessing care (F16-49, S17-30, S18-29, S18-39). Some premedical students also used their essays to call for improvements in medical education, including increased training in addressing the inequalities that exist in both society and medicine (F16-18, F1619, F16-31, S18-45, S18-29).

We come into the field very excited in hopes [of] getting involved with unique medical interventions and grandiose ideas. Yet, some of the most important and impactful work we will end up doing is simple[:] comforting of patients or working with them and their families to guarantee care, comfort, and respect of patients' wishes. (S1842)

When I volunteered in an emergency room, I witnessed the casual way in which patients who complained of pain were dismissed. I did not have access to medical records, but one patient I particularly remember was an older black lady who was crying because she was in pain. She said nobody had performed an examination on her, and when I asked a nurse, she waved me off, saying, "You get an eye for figuring out who's faking it for drugs." I was alarmed by this, but assumed she was correct, as I had almost no power in the situation. Whether or not this old woman was addicted to painkillers, wasn't it the duty of medical professionals to trust her and give her the benefit of the doubt? When filtering through the hundreds of patients who are turned 
away for being fakers, isn't it possible that a couple of them were telling the truth? (F16-33)

\section{Overarching theme: near-peer affinities}

Our narrative analysis of the premedical students' reflective essays also revealed unprompted expressions of near-peer affinities. Although students had not been instructed to reflect on the near-peer status of the in-Training authors, the essays in our dataset frequently linked the value of the blog posts to their status as narratives authored by nearpeers. Representative quotations on near-peer affinities are displayed in Table 3. Students expressed feeling more optimistic and inspired about their future careers knowing that their near-peers were writing about empathy and humanism in medicine and stated that they felt they better understood the medical school experience after reading the near-peer blog posts (S18-14, F16-5, S17-10, S17-11). Premedical students often discussed their positive affinities towards near-peer works in contrast to works authored by faculty and written in more traditional scholarly form. Some noted that it was easier to connect with the narratives because they were authored by near-peers and praised the informal style of the blog pieces (F17-28, F16-5, S17-12, S17-4, F16-1, F16-7). Several authors appreciated the honesty and "raw" nature of the narratives (F16-7, F16-5, F16-1, F16-11). However, there were also criticisms of the near-peer pieces, including that they lacked literary technique and style (F16-1, F16-6, F16-9, F16-8) and were not sufficiently nuanced in their discussion of the core humanities issues (F16-23, F16-31).

The fact that I felt emotionally involved [...] is a testament to the value of narratives. Narratives from medical students are particularly relevant to us pre-meds, because we can easily imagine ourselves in their shoes a few years in the future. (S17-4) While reading the selections from in-Training my initial reaction was surprise at their raw nature. Although each short story or poem had a clear central argument transmitted through the emotional perspective of the medical student author, they lacked the literary style and techniques I have come to expect. At first, I felt disappointed by this fact, feeling that the lack of polish took away from the worth of the selections. However, after just a couple narratives, I came to appreciate how intimate this informal style of writing can be. Since the stories are not excessively formulated or contrived, thoughts and emotions behind their writing are allowed to shine through. (F16-1)

\section{Discussion}

Our analysis found the student responses to the near-peer medical student narratives from in-Training to be significant in two ways. First, the core themes identified in the premedical student essays demonstrate engagement with landmark topics in the humanities education of medical trainees: empathic conflict, bias in healthcare, and the humanity of medicine. Second, the students frequently discussed the medical student blog posts through the lens of self-reflection, closely identifying with the near-peer bloggers' experiences and considering how they would respond to the same situations. While the first finding confirms our hypothesis regarding the utility of near-peer narratives for introducing core concepts in the medical humanities and fostering self-reflection on the 
Table 3 Selected quotations from pre-medical student essays on near-peer affinities

\section{Essay Identifier Reflective Essay Excerpt}

F16-1 While reading the selections from in-Training my initial reaction was surprise at their raw nature. Although each short story or poem had a clear central argument transmitted through the emotional perspective of the medical student author, they lacked the literary style and techniques I have come to expect. At first, I felt disappointed by this fact, feeling that the lack of polish took away from the worth of the selections. However, after just a couple narratives, I came to appreciate how intimate this informal style of writing can be. Since the stories are not excessively formulated or contrived, thoughts and emotions behind their writing are allowed to shine through.

F16-5 The honesty from these medical students really stands out throughout these narratives [...] These medical students reveal the concerns and challenges that I have always suspected would be hardest for me; however, I am comforted by the fact that these students use their experiences to grow and become stronger and better doctors.

F16-6 I found the stories to be interesting and touching, but it was an interesting adjustment to reading fiction that was not crafted by a seasoned creative writer. Some of the writing still felt very clinical or over-flourished with language that didn't fit the situation in the story. For example, I thought the story "Exam Room 3" told a very emotional and thought-provoking story, but the language felt forced, especially in phrases like, "my brain moved like molasses," and "the anguished sobs stopped me in my tracks." This is not to say that any of the writing styles in these selections negated their relevance in the field of the medical humanities. I think that understanding the experience of practicing medicine is just as much a part of studying the medical humanities as is understanding the experience of the patient. I value the stories given in this reading for their unique first-person perspective, but I don't think I'd spend time close reading the language in these narratives.

F16-7 I enjoy reading these in-Training selections, because of the rawness and honesty of the writers.

F16-8 Overall, I was relatively impressed with the quality of the writing in these essays, though I did not find them to be of the same quality as those written by more experienced physician-writers like Richard Selzer.

F16-9 I would be interested to see what kind of workshopping goes into these stories after their initial writing. In previous discussions, I've learned of writing groups or special guided editing workshops that can help authors engage with the emotions involved with their writing process and tailor their writing to showcase that. I was intrigued by the amount of medical jargon included in the text, especially when I compare it to the works that we read in class on Thursday as a part of our guest lecture. Those works appeared to be more stripped down and invested in emotion and metaphor. I do think that these works have some instructional value, but I wonder if a more engaged writing process could have yielded more cohesive work. I found that I could feel the themes of the story itself, but it was hard to connect with the writing style, which often felt cold and flat. It seemed that the authors understood which stories were particularly impactful, but they did not channel them effectively in my opinion.

F16-11 The emotion is very raw because for medical students, experiences are still new. Nothing is mundane yet.

F16-23 I know it's difficult to tackle such an expansive topic in a single paper, but I still found some ideas to be only vaguely addressed and devoid of nuance.

F16-31 A fault I see in Jennifer Tsai's piece, however, is that she puts a significant amount of emphasis on systemic biases in the hospital setting, an emphasis that I think is overestimated. Physicians are also at least partly culpable for the biases they inflict on their patients, and explaining the problem away by using the idea of systemic racism does not solve the issue. Instead, medical schools must make a greater effort to educate their students in understanding the patient as a whole, including their sociopolitical environment and their cultural norms, so that physicians in the real world are equipped to deal with a diverse patient population and can fight structural biases. 
Table 3 (continued)

Essay Identifier Reflective Essay Excerpt

F17-28 This was my favorite reading assignment so far. It was very easy to connect with the medical student and feel whatever internal conflict or emotions they struggled through. I thought it was especially helpful because I will likely never be in any of these exact situations and definitely don't have the exact same background or perspective as any of them, so it allows me to understand the lessons they've learned without having to actually live through all those experiences myself. I especially liked the emphasis on patient connection and empathy throughout the stories. I felt it shed a positive light on caring about a patient.

S17-4 The fact that I felt emotionally involved however, is testament to the value of narratives. Narratives from medical students are particularly relevant to us pre-meds, because we can easily imagine ourselves in their shoes a few years in the future. The naivety of these stories sometimes struck me - many pre-meds aspire to save lives and cure illnesses, and yet the reality often strays far from that ideal.

S17-10 All of the narratives in this book are incredibly detailed, poignant. I was moved by each and every one of them and now feel like I understand a part of medical school/doctoring that I hadn't considered would be so impactful before.

S17-11 Put simply, each medical student's experience thus far was different despite some common themes and underlying ideas. As such, the book as a whole presents a balanced idea of what it is like to be on the brink of starting your career, to be overwhelmed with newness and a sense of purpose, and to be at the bottom of the medical totem pole. I loved this book. Each reading spoke to me in a different but moving and special way. The stories were rich and diverse in themes, stories, and concepts, ranging from the idea of humor in the patient experience in "the Chair" by Ben Ferguson to the meaning of death for someone whose life is already compromised as in "Fading Memories of Love and Martinis" by Joshua Niforatos. Each author was candid, thoughtful, and eloquent in voicing their good days and bad days at the start of their medical career. As an aspiring physician myself, I found this inspiring. I hope to write and never stop writing in my own career one day. It not only gives you perspective and understanding of your purpose, your passion, and your experiences but also provides the rest of the world insight on the doctor side of the patient experience. I already said this but I'll say it again: I loved this reading and even read many other stories in the book. It is so generous of these doctors to share these ideas with us. What a privilege to get to read these.

S17-12 These series of stories in in-Training is the most interesting reading we had to do for this class so far because these are more personable, approachable, and recount real life experiences. Because I want to be a doctor as well, it gives me a myriad of unique perspectives that can prepare me for what to expect in the future. It ties in very nicely to the topics we are discussing in class and the other class textbooks, but the stories are just more relatable. I feel like I understand topics like death and doctor-patient relationships better from reading these stories.

S18-14 If these readings provided me with any consolation, it is knowing that all of these thoughtful, empathic anecdotes were written by current or recent medical students. These students were aware of this need to add humanity back into the equation of medicine, whether this be through empathizing with the patient's history or improving their patient bedside etiquette. They acknowledge their limits as physicians, not being able to resolve their patients' personal issues or illnesses that are beyond their control, but that doesn't deter them from trying to provide the best form of care that they can.

professional demands of a career in medicine, the second was an unexpected finding that further confirms the pedagogical value of integrating near-peer blogs in an undergraduate premedical humanities course. Both findings highlight the importance of writing personal narratives as medical students and reading those narratives as premedical students. 
Our analysis of the "near-peer affinities" present in undergraduate premedical students' reflective writing suggests that near-peer narratives expose premedical students to varied perspectives, which serves to strengthen and broaden their personal experiences from clinical shadowing or volunteering. The integration of near-peer narrative may play a significant role in cultivating premedical students' professional identities by attending to the demands of the profession and the social contexts in which medicine is practiced. Through their reflections on near-peer writings, these students enter medical school having developed an appreciation for the humanistic aspects of medicine and an ability to reflect on the role and duties of the physician in society. Structured engagement with near-peer writings in the undergraduate medical humanities curriculum, our research suggests, can be particularly influential in premedical students' professional identity development because it provides those who are contemplating a career in medicine the opportunity to learn from the collective experiences of medical trainees.

For educators, providing curricular material that is more easily relatable to undergraduates presents an obvious advantage in maximizing student engagement. However, this should be balanced with recognition of the novice nature of many near-peer pieces, as several study participants mentioned that the quality of the writing was at times inferior to the other reading assignments in the curriculum that were written by more experienced authors. At the same time, by demonstrating their ability to critique the quality and purpose of the medical student posts, premedical students in our study demonstrated their willingness and ability to engage in key discourses within the medical humanities.

\section{Theme 1: empathic conflict}

Our finding that many study participants wrote self-reflective essays on the topic of empathic conflict is an important outcome of this study and reveals that premedical students can discuss challenges with empathy and emotional distancing through the lens of narrative medicine in the same way as medical students. By engaging with near-peer blog posts, premedical students recognized their vulnerability to empathic conflict and the challenges with emotional distancing, and how this conflict may affect their connections with future patients and with their own personal wellbeing, issues that are well-represented in the literature on this subject (Hirsch 2007; Eikeland et al. 2014; Andersen et al. 2020). Students also recognized that reflecting on the narratives themselves was cathartic and instrumental in their own professional development. Our analysis further revealed that study participants discussed both the positive and negative effects of medical students' empathic engagement with patients and their stories and included nuanced perspectives on the structural causes of burnout, including depersonalization and imposter syndrome. Self-reflective writing normalizes discussion of empathic conflicts, which has been shown to be critical for building resilience and combating burnout in health professionals (Chen and Forbes 2014; Narayan, Stern, and Fornari 2018; Harscher et al. 2018; Pohontsch et al. 2018). Our finding that premedical students were able to recognize burnout among their nearpeers, despite not experiencing burnout themselves, may have important educational implications in allowing them to better recognize and prevent burnout in themselves in the future (Jennings 2009). 


\section{Theme 2: bias in healthcare}

The social construction of race, racial health disparities, and the persistent legacy of racism in United States health systems are frequently explored topics within health humanities research, and efforts toward racial justice within health professions education is rooted in the health humanities: ethics, medical sociology, and the history of medicine (NieblasBedolla et al. 2020). Students' essays exploring racial bias in medicine, socioeconomic disparities limiting access to healthcare, and the linguistic or cultural barriers that impact patient-provider communication provide compelling evidence that premedical students' reflections on near-peer writing can effectively encourage a deeper awareness of these topics and the development of cultural competence as defined by the AAMC. The students in our study exhibited a significant willingness to engage with near-peer writings on these complex issues rather than avoiding recognition of medicine's imperfections, evidence of their growing "structural competence" on issues of systemic racism, per Petty and colleagues (2017). In their essays, students further reflected on how near-peer narratives resonated with their own or their loved ones' experiences with bias in a healthcare setting and considered how their own implicit biases might impact their ability to provide care for their patients. We find, therefore, that reflecting on near-peer narratives provides a productive space for undergraduate premedical students' personal and professional development even before entering formal medical education, especially as it pertains to implicit bias and structural racism.

\section{Theme 3: the "humanity of medicine"}

Our analysis finds that near-peer narratives are an effective means of encouraging students to relate to their patients as people, and not just as constellations of symptoms to be cured. Entering medical students are asked to appreciate that an individual's health and wellbeing are determined by the intersection of biological, social, cultural, and psychological factors. Premedical students often shadow physicians, volunteer in clinical settings, or work in ancillary services as emergency medical technicians or scribes to develop this understanding (Association of American Medical Colleges, "Five Ways to Gain Experience without Shadowing"). Our findings show that near-peer written works can serve as an additional avenue for premedical students to reflect on their personal experiences with patients in a nascent form of narrative medicine. Students described the complex social and cultural narratives of the patients whom they had met in their premedical experiences, and how reading the near-peer pieces taught them to reflect more critically on their encounters with patients and on the structural issues within medicine and health care that contributed to these illness narratives. The premedical students in our study also reflected on how they personally would approach the patient-physician interactions and challenges described by their medical student near-peers, which is a key critical thinking skill required of medical professionals. Through their reflections, premedical students contemplated the role and duties of the physician in today's society, and how they will approach the intersection of biomedical sciences and the "human side of medicine" as they enter the medical field. 


\section{Overarching theme: near-peer affinities}

Although students were not explicitly instructed to comment on the authorship of the inTraining narratives, our analysis revealed frequent reflection on the authors' status as nearpeers. These commentaries included both positive responses to reading near-peer works as well as discussions that were more critical of the quality of novice writers. Near-peer narratives are, by the students' own estimation, accessible, engaging, and impactful introductions to foundational topics in the medical humanities. Student reflections address the pleasure of near-peer learning through narratives that were written by trainees close in academic level and age to undergraduate premedical students. Thus, we find that near-peer narratives published in online, open-access venues (e.g. blogs) serve as a crucial introduction and complement to more traditional academic prose published in peer-reviewed venues (e.g. scholarly journals, monographs, anthologies, or edited collections) for premedical students.

\section{Limitations}

This study has several limitations. Research was conducted in only one institution, and while the study population was racially and socioeconomically diverse, it may not be statistically representative of all premedical students across United States universities and colleges. As a qualitative analysis of an educational intervention, the study method did not include randomization or a comparator group, raising the possibility of selection bias among study participants. The students who participated in the study were enrolled in a medical humanities course and are not necessarily representative of the general population of premedical students. Finally, readings from in-Training were chosen for their value in premedical health humanities education and therefore are not representative of all possible near-peer creative nonfiction narratives or blogs, which may not have equal value in achieving the results described in this study.

\section{Conclusions}

This study identifies a novel pedagogical method for introducing core topics in the medical humanities through the integration of an online near-peer narrative medicine blog to augment traditional medical humanities teachings for premedical students. The premedical student essays analyzed in our study demonstrated nuanced engagement with three core themes - empathic conflict, bias in medicine, and the human side of medicine - as well as strong affinities with near-peer authors. Our results demonstrate how reading and writing about near-peer narrative accounts of medical training can provide a unique and valuable perspective on the impact of patient encounters, particularly those involving vulnerable and marginalized populations, as they shape professional identity formation for premedical and medical students. Our qualitative assessment of student responses to the in-Training readings thus underscores the value of this pedagogical method. This study finds that near-peer learning through engagement with creative nonfiction published on a medical student blog allows for critical reflection on medical education from the profession's future leaders. The ability to use near-peer narratives to facilitate empathic learning, facilitate resilience, and address bias in medicine is an opportunity that warrants further study and integration into existing premedical educational curricula. 
Acknowledgements The authors wish to thank the students who participated in the "Introduction to Medical Humanities" courses at Rice University when this research was conducted, Dr. Beverly Mitchell, instructor for the course, the Humanities Research Center at Rice University, and the Andrew W. Mellon Foundation, which provided financial support for course instruction.

\section{Declarations}

Ethics approval This study was submitted to the Rice University Institutional Review Board and approved September 14, 2016, protocol number IRB-FY2017-39.

Conflicts of interest/Competing interests The online peer-reviewed publication in-Training was founded in April 2012 by Aleena Paul and Ajay Major when they were medical students at Albany Medical College, and was incorporated as a 501(c)3 non-profit corporation in 2015. Aleena Paul and Ajay Major are unpaid volunteers for in-Training. Proceeds from in-Training book sales are paid to the 501(c)3 non-profit to financially support in-Training as an online publication, and are not paid to Ajay Major, Aleena Paul, or any other person associated with in-Training.

\section{Endnote}

${ }^{1}$ This phrase is drawn from the final line of Jimmy Tam Huy Pham's essay, "A Night at the Homeless Shelter," which was quoted frequently in students' reflective essays.

Open Access This article is licensed under a Creative Commons Attribution 4.0 International License, which permits use, sharing, adaptation, distribution and reproduction in any medium or format, as long as you give appropriate credit to the original author(s) and the source, provide a link to the Creative Commons licence, and indicate if changes were made. The images or other third party material in this article are included in the article's Creative Commons licence, unless indicated otherwise in a credit line to the material. If material is not included in the article's Creative Commons licence and your intended use is not permitted by statutory regulation or exceeds the permitted use, you will need to obtain permission directly from the copyright holder. To view a copy of this licence, visit http://creativecommons.org/licenses/by/4.0/.

\section{References}

Agius, Andee, Neville Calleja, Christian Camenzuli, et al. 2018. "Perceptions of First-year Medical Students towards Learning Anatomy using Cadaveric Specimens through Peer Teaching." Anatomical Sciences Education 11 (4): 346-357. https://doi.org/10.1002/ase.1751.

Andersen, Freja Allerelli, Ann-Sofie Bering Johansen, Jens Søndergaard, et al. 2020. "Revisiting the Trajectory of Medical Students' Empathy, and Impact of Gender, Specialty Preferences and Nationality: A Systematic Review." BMC Medical Education 20 (52). https://doi.org/10.1186/ s12909-020-1964-5.

Association of American Medical Colleges. "Five Ways to Gain Experience without Shadowing." Accessed June 28, 2019. https://students-residents.aamc.org/choosing-medical-career/article/five-ways-gainexperience-without-shadowing/.

Association of American Medical Colleges. "The Core Competencies for Entering Medical Students." Accessed May 1, 2018. https://students-residents.aamc.org/applying-medical-school/article/corecompetencies/.

Baruch, Jay M. 2013. "Creative Writing as a Medical Instrument." Journal of Medical Humanities 34 (4): 459-469. https://doi.org/10.1007/s10912-013-9243-7.

Charon, Rita, Nellie Hermann, and Michael J. Devlin. 2016. "Close Reading and Creative Writing in Clinical Education: Teaching Attention, Representation, and Affiliation.” Academic Medicine 91 (3): 34550. https://doi.org/10.1097/ACM.0000000000000827.

Chen, Isabel and Connor Forbes. 2014. "Reflective Writing and its Impact on Empathy in Medical Education: Systematic Review." Journal of Educational Evaluation for Health Professions 11 (20). https:// doi.org/10.1097/ACM.0000000000000827. 
Cheston, Christine C., Tabor E. Flickinger, and Margaret S. Chisolm. 2013. "Social Media use in Medical Education: A Systematic Review.” Academic Medicine 88 (6): 893-901. https://doi.org/10.1097/ACM. 0b013e31828ffc23.

Chou, Calvin L. and Arianne Teherani. 2017. "A Foundation for Vital Academic and Social Support in Clerkships: Learning through Peer Continuity.” Academic Medicine 92 (7): 951-955. https://doi.org/ 10.1097/ACM.0000000000001661.

Cole, Thomas R., Nathan S. Carlin, and Ronald A. Carson, eds. 2015. Medical Humanities: An Introduction. New York: Cambridge University Press.

Coleman E. and E. O'Connor. 2019. "The Role of WhatsApp in Medical Education: A Scoping Review and Instructional Design Model." BMC Medical Education 19 (279). https://doi.org/10.1186/ s12909-019-1706-8.

Eikeland, Hanne-Lise, Knut Ørnes, Arnstein Finset, and Reidar Pedersen. 2014. "The Physician's Role and Empathy: A Qualitative Study of Third Year Medical Students.” BMC Medical Education 14 (165). https://doi.org/10.1186/1472-6920-14-165.

Eysenbach, Gunther. 2008. "Medicine 2.0: Social Networking, Collaboration, Participation, Apomediation, and Openness." Journal of Medical Internet Research 10:22. https://doi.org/10.2196/jmir.1030.

Goldie, John Gerald Scott. 2016. "Connectivism: A Knowledge Learning Theory for the Digital Age?" Medical Teacher 38 (10): 1064-1069. https://doi.org/10.3109/0142159X.2016.1173661.

Harscher, Heidi von, Nathaly Desmarais, Robert Dollinger, Seth Grossman, and Scarlett Aldana. 2018. "The Impact of Empathy on Burnout in Medical Students: New Findings." Psychology, Health and Medicine 23 (3): 295-303. https://doi.org/10.1080/13548506.2017.1374545.

Hirsch, Elliott M. 2007. "The Role of Empathy in Medicine: A Medical Student's Perspective." Virtual Mentor 9 (6): 423-427. https://doi.org/10.1001/virtualmentor.2007.9.6.medu1-0706.

in-Training. Accessed September 4, 2019. https://in-training.org/.

Jennings, M. L. 2009. "Medical Student Burnout: Interdisciplinary Exploration and Analysis." Journal of Medical Humanities 30 (4): 253-269. https://doi.org/10.1007/s10912-009-9093-5.

Jones, Therese, Delese Wear, and Lester D. Friedman, eds. 2014. Health Humanities Reader. New Brunswick: Rutgers University Press.

Kanter, Steven L. 2008. "Toward a Sound Philosophy of Premedical Education.” Academic Medicine 83 (5): 423-424. https://doi.org/10.1097/ACM.0b013e3181734623.

Knobloch, Alexander C., Christy J.W. Ledford, Sean Wilkes, and Adam K. Saperstein. 2018. "The Impact of Near-peer Teaching on Medical Students' Transition to Clerkships.” Family Medicine 50 (1): 58-62. https://doi.org/10.22454/FamMed.2018.745428.

Lamothe, Martin, Emilie Boujut, Franck Zenasni, and Serge Sultan. 2014. "To be or not to be Empathic: The Combined Role of Empathic Concern and Perspective taking in Understanding Burnout in General Practice.” BMC Family Practice 15 (15). https://doi.org/10.1186/1471-2296-15-15.

Lockspeiser, Tai M., Patricia O’Sullivan, Arianne Teherani, and Jessica Muller. 2008. "Understanding the Experience of being taught by Peers: The Value of Social and Cognitive Congruence." Advances in Health Sciences Education: Theory and Practice 13 (3): 361-72. https://doi.org/10.1007/ s10459-006-9049-8.

Major, Ajay and Aleena Paul, eds. 2016. in-Training: Stories from Tomorrow's Physicians. United States: Pager Publications, Inc.

Narayan, Gita Anjali, Penny Stern, and Alice Fornari. 2018. "Effect of Reflective Writing on Burnout in Medical Trainees.” MedEdPublish 7 (4): 16. https://doi.org/10.15694/mep.2018.0000237.1.

Nieblas-Bedolla, Edwin, Briana Christophers, Naomi T. Nkinsi, Paul D. Schumann, and Elizabeth Stein. 2020. "Changing how Race is Portrayed in Medical Education: Recommendations from Medical Students." Academic Medicine 95 (12): 1802-1806. https://doi.org/10.1097/ACM.0000000000003496.

Petty, JuLeigh, Jonathan M. Metzl, and Mia R. Keeys. 2017. "Developing and Evaluating an Innovative Structural Competency Curriculum for Pre-health Students." Journal of Medical Humanities 38:459471. https://doi.org/10.1007/s10912-017-9449-1.

Pham, Jimmy Tam Huy. 2012. "A Night at the Homeless Shelter." in-Training website. December 21. Accessed February 6, 2021. https://in-training.org/a-night-at-the-homeless-shelter-654.

Pohontsch, N. J., A. Stark, M. Ehrhardt, T. Kötter, and M. Scherer. 2018. "Influences on Students' Empathy in Medical Education: An Exploratory Interview Study with Medical Students in their Third and Last Year.” BMC Medical Education 18 (231). https://doi.org/10.1186/s12909-018-1335-7.

Ruiz, Jorge G., Miachel J. Mintzer, and Roseanne M. Leipzig. 2006. "The Impact of E-learning in Medical Education." Academic Medicine 81 (3): 207-212. https://doi.org/10.1097/00001888-20060 3000-00002. 
Tamachi, Shameena, James A. Giles, Tim Dornan, and Elspeth J. R. Hill. 2018. "'You understand that whole big situation they're in': Interpretative Phenomenological Analysis of Peer-assisted Learning." BMC Medical Education 18 (1). https://doi.org/10.1186/s12909-018-1291-2.

Wald, Hedy S., Jordan White, Schmuel P. Reis, Angela Y. Esquibel, and David Anthony. 2019. "Grappling with Complexity: Medical Students' Reflective Writings about Challenging Patient Encounters as a Window into Professional Identity Formation.” Medical Teacher 41 (2): 152-160. https://doi.org/10. 1080/0142159X.2018.1475727.

Publisher's Note Springer Nature remains neutral with regard to jurisdictional claims in published maps and institutional affiliations.

\section{Authors and Affiliations}

\section{Rachel Conrad Bracken ${ }^{1}$ (D) Ajay Major ${ }^{2} \cdot$ Aleena Paul $^{3} \cdot$ Kirsten Ostherr $^{4}$}

1 Department of Family and Community Medicine, Northeast Ohio Medical University, 4209 St. Rte. 44, Rootstown, OH 44272, USA

2 Section of Hematology/Oncology, University of Chicago, Chicago, IL, USA

3 Department of Medicine and Department of Pediatrics, Donald and Barbara Zucker School of Medicine At Hofstra/Northwell, Hempstead, NY, USA

4 Rice University, Houston, TX, USA 